\title{
Meissen Porcelain: Precision, Presentation, and Preservation. How Artistic and Technological Significance Influence Conservation Protocol
}

Nicole Peters

West Virginia University

Follow this and additional works at: https://researchrepository.wvu.edu/etd

\section{Recommended Citation}

Peters, Nicole, "Meissen Porcelain: Precision, Presentation, and Preservation. How Artistic and Technological Significance Influence Conservation Protocol" (2011). Graduate Theses, Dissertations, and Problem Reports. 756.

https://researchrepository.wvu.edu/etd/756

This Thesis is protected by copyright and/or related rights. It has been brought to you by the The Research Repository @ WVU with permission from the rights-holder(s). You are free to use this Thesis in any way that is permitted by the copyright and related rights legislation that applies to your use. For other uses you must obtain permission from the rights-holder(s) directly, unless additional rights are indicated by a Creative Commons license in the record and/ or on the work itself. This Thesis has been accepted for inclusion in WVU Graduate Theses, Dissertations, and Problem Reports collection by an authorized administrator of The Research Repository @ WVU. For more information, please contact researchrepository@mail.wvu.edu. 
Meissen Porcelain: Precision, Presentation, and Preservation.

How Artistic and Technological Significance

Influence Conservation Protocol.

\author{
Nicole Peters \\ Thesis submitted to the College of Creative Arts \\ at West Virginia University \\ in partial fulfillment of the requirements \\ for the degree of \\ Master of Arts \\ in \\ Art History
}

Approved by

Janet Snyder, Ph.D., Committee Chair

Rhonda Reymond, Ph.D.

Jeff Greenham, M.F.A.

Michael Belman, M.S.

Division of Art and Design

Morgantown, West Virginia

2011

Keywords: Meissen porcelain, conservation, Fürstenzug Mural, ceramic riveting, material substitution, object replacement

Copyright 2011 Nicole L. Peters 


\section{ABSTRACT \\ Meissen Porcelain: Precision, Presentation, and Preservation. How Artistic and Technological Significance Influence Conservation Protocol.}

\section{Nicole Peters}

This paper investigates the technological and historical significance of the invention of Meissen porcelain and how these factors impact certain restoration and conservation protocol. The diversity and range of objects produced at the Meissen studio paired with the artistic genius of their design repositioned European ceramics as a superior craft form among its pottery-producing competitors. The ware's enthusiastic reception amongst upper-class European society established the pieces as being highly-valued and prompted their widespread recognition. What resulted was an efflorescence of creativity, artistic and technical accomplishments, and an original aesthetic quality that initiated a new conceptual reframing of how ceramic media could be presented. Throughout the past three centuries, Meissen porcelain has continued to be coveted, collected, and exhibited. As a result, the work requires the aid of conservation science in order to preserve its cultural and material integrity.

For a body of work so steeped in precision, presentation, and material science, certain attributes that are crucial to Meissen porcelain's identity must be taken into account prior to the assembly of an appropriate conservation protocol. By considering these factors, conservators, museum professionals, and historians are able to devise more informed and appropriate decisions involving the direction of a conservation route for an individual object. For the purposes of this argument, three case studies are observed: ceramic riveting, material substitution and/or object replacement, and a condition assessment of the Fürstenzug mural in Dresden, Germany. All three situations present some of the most visually-intrusive and structurally-jeopardizing tactics pertaining to conservation methodologies. The historical, artistic, and technological attributes of Meissen porcelain are assessed in an attempt to devise proper treatment plans for all three case studies.

The purpose of this paper is not to discredit or undermine alternative porcelain media and the restorations applied to their framework. Instead, its objective is to bring an individuality to Meissen porcelain and the restorative processes applied in its conservation. This, in turn, contributes to and expands upon preexisting conservation methodologies involving the restoration of porcelain media. The main goal is to educate and inform art historians, museum professionals, and conservators alike about the particularities of specific clay media and the significance of their individual attributes within ceramic art. 


\section{DEDICATION}

This thesis is dedicated to my grandmother, Shirley J. Pinchok, who has spent her life loving, supporting, and inspiring her family. 


\section{ACKNOWLEDGMENTS}

I would like to thank my graduate committee for devoting their ongoing support, guidance, flexibility, and constant encouragement during my graduate education. My thesis research has benefited tremendously because of your

insight and expertise. I would especially like to thank Dr. Janet Snyder; you are a blessing and inspiration to us all.

Also, I would like to thank my family and friends for their love and support, which continues to carry me through both my personal and professional endeavors. I am forever grateful for your presence in my life. Without you, none of this would be possible. Thank you ever so much. 
TABLE OF CONTENTS

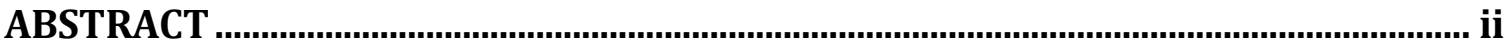

ACKNOWLEDGEMENTS ................................................................................................. iv

LIST OF ILLUSTRATIONS ............................................................................................

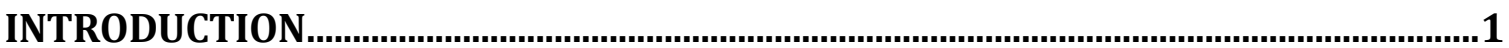

CHAPTER ONE: “White Gold” ...........................................................................................5

CHAPTER TWO: European Taste and the Baroque Aesthetic....................................18

CHAPTER THREE: Impact and Expansion.....................................................................35

CASE STUDY 1: Ceramic Riveting ............................................................................ 40

CASE STUDY 2: Material Substitution/ Object Replacement .....................................55

CASE STUDY 3: Fürstenzug Mural.............................................................................65

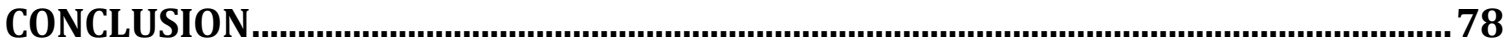

ILLUSTRATIONS

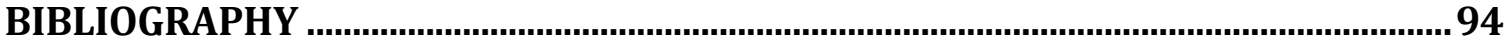




\section{Illustrations}

$\begin{array}{lll}\text { Figure } & \text { Page }\end{array}$

1 Map of Cape Route to India, "Cape of Good Hope,"

http://www.ambassadors.net/archives/issue19/profile.htm ...............81

2 Example of Seventeenth Century German Architecture, Goslar,

Saxony, Germany .................................................................................................81

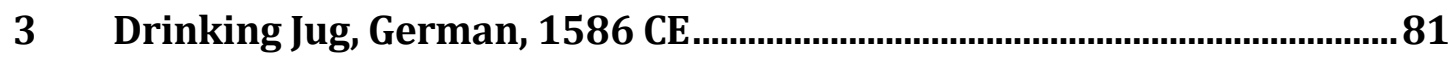

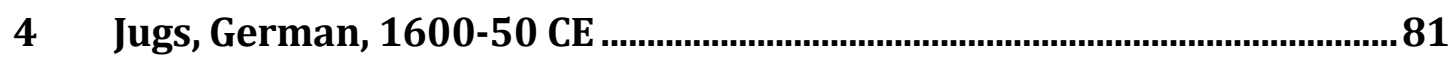

5 Nicolaes Gillis, Breakfast Piece, 1622-32 CE, location unknown .............81

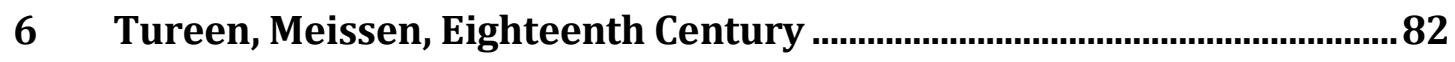

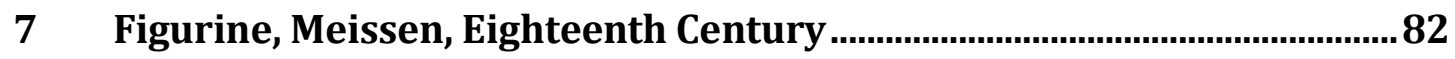

8 Coat of Arms Teapot, Meissen, Eighteenth Century

9 Vase, Blue and White Design, Meissen, 1723-25 CE .................................. 82

10 Vase, Kakiemon Style of Arita Japanese Porcelain, Meissen, 1730 CE

11 Tea Service, German, Silver-gilt Stand and Meissen Porcelain, Eighteenth Century.

12 Centerpiece from the Table Service of Count Burchardt Christoph von Munnich, Meissen, 1735-36 CE..

13 Benevenuto Cellini, Salt Cellar, or Saliera, 1543 CE,

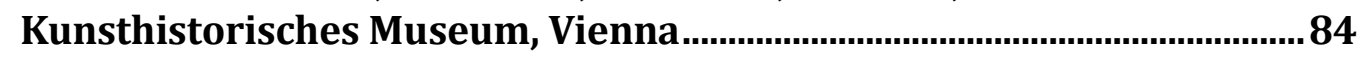

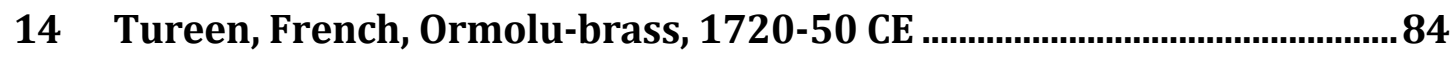

15 Console Table, Gilt Wood, Italian, 1680-90 CE....................................... 84

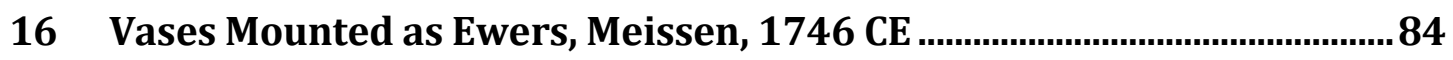

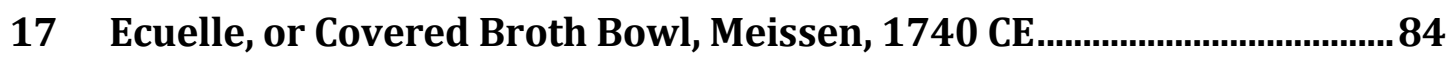


18 St. Teresa Bust, Meissen, 1743-44 CE

19 Gian Lorenzo Bernini, St. Teresa in Ecstasy, 1652 CE, Cornaro Chapel, Santa Maria della Vittoria, Rome

20 Pope Pius V, Meissen, 1743-44 CE 85

21 Giovanni Arrighi, Reliquary Bust of St. Urban, 1706 CE 85

22 Johann Joachim Kaendler, Equestrian Monument model, Meissen, 1753 CE

23 Pietro Tacca, Equestrian Statue of Phillip IV, 1634-40 CE, Spain . 85

24 Johann Joachim Kaendler, Crinoline Group, Meissen, 1737 CE .................86

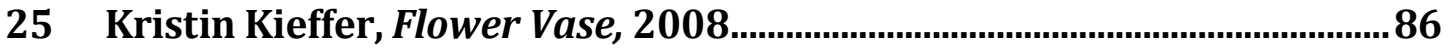

26 Meissen Gothic Prototype Design, Meissen, Eighteenth Century .............86

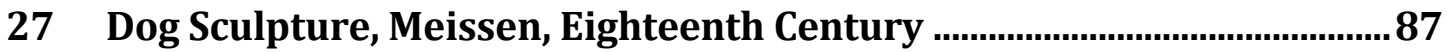

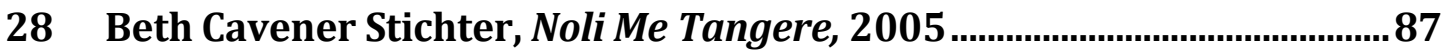

29 Silvie Granatelli, Swan Handle Cream Pitchers, 2008...............................87

30 Swan Handle Ewer, Meissen, Eighteenth Century ...................................... 87

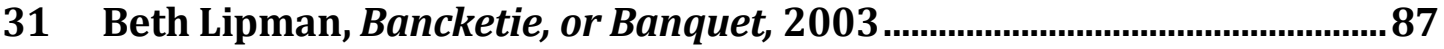

32 Contemporary Ceramic Riveting, Twentieth Century ..............................88

33 Blue-Onion Pattern Serving Dish, Meissen, Eighteenth Century $\ldots . . . . . . . . . .88$

34 Blue-Onion Pattern Serving Dish, Detail of Riveting, Meissen, Eighteenth Century

35 Diagram of Signatures Applied on Meissen Porcelain 88

36 Metal-spout Replacement and Handle Reinforcement on Chinese Porcelain. 88

37 Iron Dowel on Meissen Serving Dish, Eighteenth Century, Private Collection 
38 Forged Bronze Replacement Handle, Meissen Porcelain

Teacup, Nineteenth Century ........................................................................89

39 Meissen Figurine with Wooden Replacement, Front .................................89

40 Meissen Figurine with Wooden Replacement, Back ...................................89

41 Meissen Figurine with Wooden Replacement, Detail ..................................89

42 Fürstenzug Mural, 1907, Saxony, Germany .................................................90

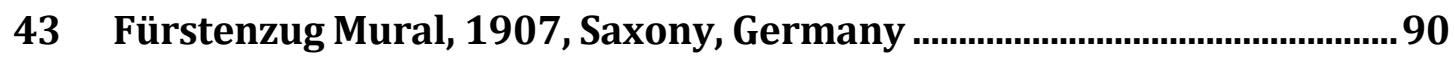

44 Fürstenzug Mural, Grand Feu Colors, detail, 1907, Saxony,

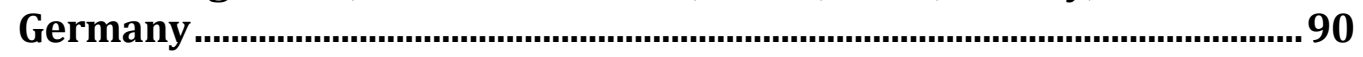

45 Fürstenzug Mural, Contemporary Figures, detail, 1907,

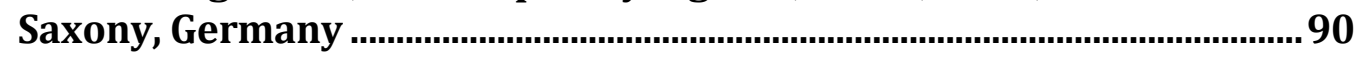

46 Chemical Composition of Meissen Porcelain ...............................................91

47 Chemical Composition of Chinese Porcelain ....................................................

48 X-Ray Comparison of Meissen and Contemporary Porcelains.................91

49 Detail of Decoration on Bottger Porcelain .................................................... 91

$50 \quad$ Example of Late $19^{\text {th }}$ Century Ceramic Tile Press........................................91

51 Fürstenzug Mural, Slip Pigment, detail, 1907, Saxony,

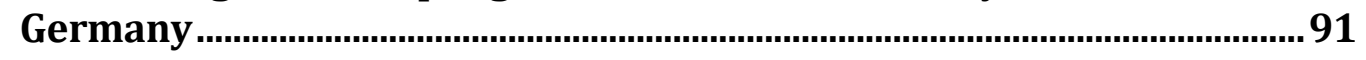

52 Fürstenzug Mural, Tile Discoloration, detail, 1907, Saxony,

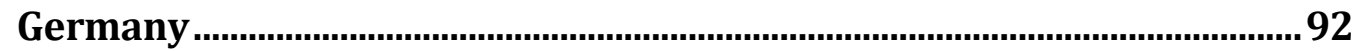

53 Fürstenzug Mural, Tile Discoloration, detail, 1907, Saxony, Germany.

54 Fürstenzug Mural, Tile Separation, detail, 1907, Saxony, Germany.

55 Fürstenzug Mural, Lateral Cracking, detail, 1907, Saxony, Germany. 
56 Fürstenzug Mural, Lateral Cracking and Pigment Discoloration, detail, 1907, Saxony, Germany ...................................................................93

57 Fürstenzug Mural, Yellowing Adhesive, detail, 1907, Saxony,

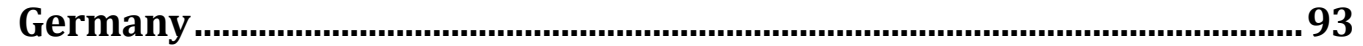




\section{Introduction}

Dating back to the earliest examples of ceramic restoration found in mideighteenth-century China, restorative processes have evolved in not only the procedures and protocol applied in these restorations, but also in the identity of the restorer and in the aesthetic and structural quality of the final piece. Depending on the context of the ceramic ware (i.e. age, culture, physical properties and aesthetics) certain restoration efforts seem to enhance the historical context and aesthetic quality of the object whereas other efforts seem to mute these characteristics. This dilemma creates an open forum for present-day conservators to discuss the implementation of certain ethical protocols and responsibilities in order to properly restore, conserve, and preserve these artifacts. Concerning the restoration of ceramic media, it is vital for the conservator to recognize and understand the composition of the clay body, the firing and decorative processes involved, and the historical significance of the ware. In some cases the compositional makeup of the clay body serves as a primary means of the ware's identity, as evident in the porcelain works produced by the Meissen factory beginning in the early eighteenth century.

Within the realm of ceramic media, Meissen porcelain, along with seventeenth- and eighteenth-century Chinese export ware, dominates fine art auction houses (such as Christie's and Sotheby's), art museums, and antique shops. Because of this, these two types of ceramic wares are highly trafficked through conservation labs as well, in order for the pieces to be treated and stabilized for sale or exhibition. The common thread that connects both Meissen and Chinese ceramic 
wares is the core composition of their clay bodies- porcelain. This material identification positions them into a special category amongst ceramic media. Although the people of Jiangxi Province, China were responsible for porcelain's initial discovery in the six century C.E and the first to produce wares made of this highly valued material, it was the Meissen factory that challenged and approached the material in a truly original manner. The Meissen factory not only devised an original recipe for the first European porcelain (that some consider to be superior both structurally and aesthetically to that of China) but also applied the material in a manner that reflected the politics, technological achievements, and fine art of the eighteenth century.

As Meissen historian Otto Walcha has thoroughly dissected in his writings concerning the historical significance and artistic genius of Meissen porcelain, the body of work reconfigured the set standard of clay media throughout Europe in the eighteenth century. While Janet Gleeson, in her "Arcanum," unravels the romantic tale behind the creation of this "white gold" through the account of the brilliant insight and contributions of both Bottger and Tschirnhaus that inspired years of original artistic development applied to the ware. These writings outline why the works from Meissen are to be considered revolutionary examples of invention, craftsmanship, and refinement, and also encourage the reasoning behind why their legacy is one that needs to be preserved.

The scientific studies and publications of ceramic media's restoration by conservators Nigel Williams and Stephen Koob provide admirable comprehensive information about the technical restoration procedures applied on various clay 
surfaces, as well as that of porcelain's. The research and application of the information provided by these scientists have come to be a milestone in the categorization and designation of subcategories existing within ceramic media conservation. Chris Caple's contribution of clarifying and expanding upon conservation ethics in his "Judgement, Method, and Decision Making," addresses the importance of not only having an appropriate conservation protocol, but also stresses the relevance of thorough historical and technical research that is to be executed prior to the implementation of said protocol on an artifact.

Because of the diversity and range of artifacts, both historical and artistic, the treatment of these objects can vary substantially. Conservators have numerous things to consider upon devising a conservation plan: materials, age of artifact, level of degradation, stability, fragility, and aesthetic and cultural integrity are just a few of the many factors impacting treatment. Naturally, it takes a great deal of time and effort to define and categorize individual restoration cases and place them into a new subcategory within conservation methodologies; especially in the genre of objects conservation. Because objects conservation consists of the most-broad spectrum of treatable media than any other conservation specialization, categories within this genre are somewhat vague and encompass a great deal of information that is often overlooked due to the lack of clarity and attention brought to each case in point.

Following this trend is the mass-categorization of ceramic restoration. Claybased artifacts contain diverse properties, ranging from and object's compositional makeup to the firing and decorative processes applied to the ware. By performing 
an in-depth analysis on a particular body of work within clay-based artifacts, such as Meissen porcelain, specific technical nuances and pertinent material information is exposed and can be utilized in the conservation of its legacy, both technically and conceptually. This paper analyzes the technological, artistic, and art historical significance behind the works created at Meissen in an attempt to devise an informed and appropriate conservation scheme for three specific case studies: a glued and riveted bowl from a Meissen dinner service, object replacement or substitution applied to Meissen ware, and the deterioration of the Fürstenzug mural in Saxony, Germany.

The specific case studies outlined in this paper provide insight on how European porcelains may be treated. By combining the fundamental processes of porcelain restoration with new techniques discovered from the investigation of Meissen porcelain, the conservator is able to expand upon preexisting methodologies in conservation science. As a result, they are able to contribute to the overall body of knowledge concerning the methods of porcelain conservation. Through the bifurcation of this thesis involving Meissen porcelain and both its history and conservation, a new type of knowledge base emerges. It is one that is approachable by historians and conservators alike, and can be identified as a middle-ground source between the two divisions. The overall objective of this analysis is to educate and inform individuals from both sectors, unveiling pertinent information from both fields and points of view. 


\section{Chapter One: "White Gold"}

Chinese ceramics had a tremendous impact, both technologically and aesthetically, on European countries' taste and style preferences in the seventeenth and eighteenth centuries. With the production of porcelain having already been established in China for nearly one thousand years, producers of Chinese porcelain objects had time to develop the ware into a refined and mature product. By the early seventeenth century Chinese porcelain had become a highly sought-after possession in the European courtly circles. The desire for a clean, white, durable ceramic material drove the search for the first hard-paste European porcelain. The establishment of the Meissen porcelain studio in the early eighteenth century repositioned Saxony as the revolutionary leader in porcelain production ahead of their French, Italian, and English soft-paste and faience-producing competitors. The innovation of a locally produced porcelain freed the Meissen studio's artistic and technological dependency from the limits imposed by China's porcelain aesthetics and artistic design. This freedom, accompanied by the art and spirit of the Baroque and Rococo aesthetic, allowed for the transformation of experimental porcelain objects into ware received by courts and critics as "high or fine art" within the span of just forty years. ${ }^{1}$ This transformation encouraged the redefinition of boundaries of the material, creating a new conceptual reframing of how ceramic media could be presented. ${ }^{2}$

1 By the year 1750, forty years after the initial Meissen porcelain recipe was established, the works being produced had already been well-received and considered highly-regarded by European courts and society.

2 Otto Walcha, Meissen Porcelain, (New York: Putnam 1981), 61. 
It is important to address the significance of Chinese porcelain, for if there had been no high quality ceramic craft in China, there would have been no porcelain production in Meissen. Chinese export ware first appeared in Europe in the 1520s, but did not begin to influence Western taste until the seventeenth century, when blue and white wares were brought in large quantities via the newly-discovered Cape route to India. ${ }^{3}$ [Figure 1] There is evidence that during the seventeenth century alone, over three million blue and white wares from China were distributed throughout Eastern Europe. ${ }^{4}$ Among the various European collectors, it was the Elector of Saxony, Frederick Augustus I (or Augustus the Strong as he preferred) whose love of the brilliant white material and whose financial and political sponsorship produced the tremendous incentives that resulted in the creation of Saxon "white gold" during his reign (1697-1706). His lavish and extravagant personality expressed itself in every aspect of his lifestyle: from costly parties and ceremonies and to his possessions of fine art and exotic goods. Augustus the Strong held the most extensive collection of Chinese export ware in all of Europe at the time. ${ }^{5}$ In addition, Augustus was a devoted patron of the newly developing sciences and technologies, and even appointed one of the alchemists who would later

${ }^{3}$ Clare Le Corbeiller and Alice Cooney Frelinghuysen, "Chinese Export Porcelain: Patterns of Exchange," Metropolitan Museum of Art Bulletin 60 (2003): 8.

William Burton, Porcelain: Its Nature, Art, and Manufacture. (London: B.T. Batsford Ltd., 1906), 163.

${ }^{4}$ Le Corbeiller and Cooney Frelinghuysen, 5.

5 Janet Gleeson, The Arcanum: The Extraordinary True Story, (New York: Warner Books, 1998), 13. 
become co-creator of Meissen porcelain, Ehrenfried Walther von Tschirnhaus, to be a member of the Dresden court. ${ }^{6}$

Alchemists Ehrenfried Walther von Tschirnhaus (1651-1708) and Johann Bottger (1682-1719) created the first European hard-paste porcelain in Meissen Germany in the late Baroque period, approximately in the year $1710 .^{7}$ The seventeenth and eighteenth centuries proved to be a fertile ground politically, scientifically, industrially, and artistically for the invention to occur. But what was the force that drove this curiosity and fascination with what is now known as the phenomenon of Meissen porcelain? Why were competing faience-producing countries like France and Italy ill-equipped to achieve such advances while Germany's conditions were suitable for the creation of porcelain to evolve and flourish? It comes down to a ruler's obsession for high quality craft and his love for Asian aesthetics, his personal interest in developing technology, as well as his desire for the extravagant and exotic. The interests of Augustus the Strong paired with his entrapment of a brilliant young alchemist held against his will until he produced a recipe for either gold or porcelain resulted in "white gold," a material that permanently repositioned Meissen's status in the ceramic world.

\section{${ }^{6}$ Burton, 171.}

${ }^{7}$ Bottger worked in collaboration with Count Ehrenfried Walther von Tschirnhaus, noblemen-scientist, on the discovery of the European version of hard paste porcelain- that being a clay body comprised of kaolin and feldspar. Though similar to Chinese porcelain in that it contained kaolin, it differed in its utilization of a calcareous flux (usually alabaster). This created greater hardness and infusibility, ultimately requiring a greater heat to fire it resulting in a durable, vitrified, semitranslucent clay body which European soft-paste porcelain could never achieve due to its low melting point and opaque clay body. 
It may be presumed that Augustus's infatuation with the material was shared amongst German collectors and craftsmen alike; the manner in how the Chinese worked the material was unlike anything they had ever seen. In contrast to what had been the current trend in Germany in regards to painting, architecture, and craft object, the presentation of these ornate, crisp, semi-translucent porcelain objects would have created an almost ethereal impression or appearance. The dark, rich palettes of paintings, solid stone and ponderous architecture, and the heavy, coarse, earth-toned stonewares of the time would have contrasted profoundly with the bright, lightweight, aesthetically foreign Chinese ware. [Figure 2-3]

In addition to the initial formal qualities of Meissen porcelain, another consideration concerns the position of Germany and the rest of Europe in terms of scientific theoretical thought during the seventeenth century. In medicine, bloodletting was still a popular practice, people were just beginning to establish the word "science" and its appropriate definition, and alchemists still believed that minerals and ore were planted like seeds by God, left in the Earth for thousands of years to expand and grow, allowing the material to become close to the surface to be mined. ${ }^{8}$ Whereas the stonewares of Germany were fairly porous, meaning that bacteria and dirt were able to be absorbed by the ware causing potential hazard to those who drank or ate from it, Chinese porcelain was completely vitreous, meaning that it had a watertight surface. Not only was porcelain aesthetically clean, but people believed it to be sanitary and sterile. By using porcelain wares, one would essentially be "protected from poisons such as arsenic, aconite, and mercury" in

\footnotetext{
${ }^{8}$ Gleeson, 6.
} 
addition to dangerous bacteria, a fairly large concern due to episodes of disease and the Black Plague that had occurred throughout Europe, leaving approximately 40,000 corpses in Vienna alone in the seventeenth century. ${ }^{9}$

In addition to the political and sanitary motivations for compelling the creation of an indigenously European porcelain, there was financial support initiated by the Saxon government for the material to be produced locally. The Germany economy was still recovering from the devastation of the Thirty Years' War, a battle initiated by the struggle between the Protestant and Catholic religious sects, as well as recovering from the catastrophe of the Black Plague. ${ }^{10}$ Though Saxony and surrounding areas were not thriving metropolitan centers, they were far from desolate post-war wastelands. As German historian S.H. Steinberg states, "What happened throughout the seventeenth century [in Germany] was a reorientation of industry, trade, and commerce."11 It was essentially the most strategic and optimal time for the country to make socio-economic and political modifications, and as the Great Elector, Augustus the Strong was determined to make this happen by brute force if necessary. According to Pennington's "Seventeenth Century Europe" regarding the issue of forced economic protocols, "He

${ }^{9}$ Gleeson, 42.

Boris Velimirovic and Helga Velimirovic, "Plague in Vienna," Reviews of Infectious Diseases 11 (1989), 812.

10 “Thirty Years' War homepage," http://www.strategos.demon.co.uk/tywhome/ "BBC Radio 4: Voices of the Powerless," August, 2002, http://www.bbc.co.uk/radio4/history/voices/voices_salisbury.shtml

${ }^{11}$ S.H. Steinberg, The Thirty Years' War and the Conflict for European Hegemony 16001660. (New York: W.W. Norton \& Co., 1966), 108. 
[the Great Elector] did not so much help his subjects to achieve prosperity as impose it on them." 12 The message was clear: be successful or be punished, any economic development was better than stagnation. Hence, extensive efforts to help stimulate the economy were allotted to an array of trades and technologies: textiles, mining, industry, trade, art, and others. In Saxony, there was a movement directed by Augustus the Strong to become a self-sufficient state. This seems a logical step for Augustus to gain political esteem, ultimately helping to position him in the running for King of Poland, in addition to benefit from the profits of increased taxes on businesses. Also saving Augustus the Strong a great deal of money was the fact he would no longer have to invest in expensive import trade shipments as long as the product was being produced locally.

It was the combination of a newly developed scientific breakthrough paired with a team of equipped artisans who knew how to appropriately interact with the material that allowed the white clay to find a "ready market whose exquisite quality was immediately recognized." 13 Not only did the ware dominate craft markets, but major financial support for the factory arose because a convergence of situations occurred. Augustus the Strong was busily engaged in furnishing his various palaces with nothing but the porcelain; these include his Baroque palaces in Dresden and Warsaw, and the unforgettable Zwinger Palace complex also located in Dresden. The popularity of the ware improved local economy by producing wares for sale and

12 D.H. Pennington, Seventeenth Century Europe. (New York: Holt, Rinehart and Winston, Inc., 1970), 69-70.

13 W.B. Honey, Dresden China; an introduction to the study of Meissen porcelain. (New York: Tudor Publishing Co., 1946), 32. 
export, employing numerous trade fleets, local artisans, and craft dealers, and eventually leading to the reorganization of the industry via laudable mass production methods. ${ }^{14}$

In order to understand the magnitude of this exotic substance's impact in terms of aesthetic quality, it is necessary to briefly rehearse the significance of ceramic works in pre-porcelain production Germany. ${ }^{15}$ The region is abundant in natural resources and mineable raw materials. The land contains inexhaustible amounts of kaolin and different clay types and is rich in numerous metals and oxides used for glaze colorants. ${ }^{16}$ It is a common misunderstanding that pottery production in Germany during the sixteenth and seventeenth centuries was deteriorating. The earthy stonewares of Westerwald and Raeren were quite popular amongst the middle-class and fulfilled the basic need for utilitarian vessels. ${ }^{17}$ [Figures 3-4] Ware was earth-toned, largely geometric in form, and somewhat rudimentary in appearance. Decoration and carvings were applied, but in a loose, imprecise manner that left the pieces with an unrefined quality. However, the pieces were functional and served ordinary people's everyday needs

${ }^{14}$ Kingery, 175.

${ }^{15}$ It is important to note that Germany did not become a unified state until 1871 after the defeat of France in the Franco-Prussian War. Prior to the war, Germanic lands existed as separate, independent states. The use of the word [Germany] in this context is meant to imply and include the various independent states before their unification.

${ }^{16}$ D.A. Holdridge, The Fine Ceramics Industry in Germany during the period 1939-1945 (London: His Majesty's Stationary Office, 1950), 7.

${ }^{17}$ David Gaimster, German Stoneware 1200-1900: Archaeology and Cultural History (British Museum Press, 1997), 127. 
and met the requirements for utility while adorning many lower- to middle-class table settings.

An example of this type of utilitarian role of German saltware can be seen in Dutch artist Nicolaes Gillis' Breakfast-piece. [Figure 5] The Siegburg jug complements the still life and holds place amongst the other ordinary objects. It contributes to but does not dominate the overall composition and table setting. The jug is one object within the arrangement and serves a utilitarian function. Hypothetically, Gillis's painting serves as a metaphor of saltware's presence in Germany at this time; it fulfilled the basic requirements of utility but did not aesthetically surpass any other craft or trade object in terms of technical superiority. It is not until the elaborate table services from the Meissen factory that the ceramic object becomes the focal point of the dining experience. These carefully thought out arrangements possessed the ability to implicate or enforce social cues and behavior. While German stoneware during the sixteenth and seventeenth centuries was pleasant and visually appealing, ultimately it did not challenge the viewer to find and comprehend its meaning nor did it project a great deal of aesthetic complexity. It was not until the 1730s when the Meissen factory began to produce revolutionary work in Europe that ceramic art expressed ideas of scholarship and refinement.

Although bearing the dual burden of being held accountable for creating a durable porcelain body and of putting the ware into mass production, the artists and designers employed at the Meissen factory managed to apply new alternative artistic interpretations to the media. They began to guide the work away from the 
familiar Chinese export ware copies and began to inform the pieces with accordance to their individual strengths and trades. These efforts were aided by technological advancements in pigment and glaze composition as well as by some general developments in material sciences regarding other forms of decorative arts, such as woodworking, silversmithing, and textile manufacturing. ${ }^{18}$ This exposure resulted in work that embraced the fine and decorative arts, and corresponded to the music and theater productions of the late Baroque and Rococo. The ceramic ware during these periods (which directly coincides with the height of Meissen porcelain production) echoed the spirit of sculptures and paintings by artists such as Bernini and Jean-Antoine Watteau; it celebrated decadence, food and drink, hearty company, and ideals of living and enjoying the moment at present.

Precision, presentation, and elegance are three dominant attributes of the aesthetic value of the work. The scientific notoriety paired with the skilled handling of the seemingly delicate material allowed Meissen porcelain works to exist beyond the constraints of mere craft or trade object. These works challenged the notion of how porcelain had been approached by associating the material with a sculpture medium rather than a pottery medium.

Not only was Johann Bottger credited with being partly responsible for the creation of the new material, but also his original concept of how the factory should function was innovative. Bottger employed workers who were individual artists in their own right, many of whom had artistic training in other fields but had perhaps never worked with clay. The goal was to allow artists with different sets of skills

${ }^{18}$ A. D'Albis, "The History of Innovation in European Porcelain Manufacture and the Evolution of Style: Are They Related?" Technology and Style. 2 (1986): 401. 
and capabilities to bring their knowledge to the studio. The slate of artists hired at the factory consisted of painters, sculptors, silversmiths, pewterers, and also potters. In fact, Bottger insisted that no Chinese artists or craftsmen be brought in to participate in the creation of the ware; he felt that by keeping native European artisans active in the creative process there would be an original European aesthetic applied to the chinoiserie, or as Meissen porcelain historian Otto Walcha states, a "European flavor in the Asian flora."19 This type of diverse studio personnel was very atypical for ceramic workshops during the seventeenth and eighteenth centuries.

Another biproduct of Bottger's enforcement of diverse artists (within media choice) was simply that each artist would have a different interpretation of how a culture could be represented, and would have had the artistic freedom to visually express these views. The products were sometimes peculiar but as a result of these odd iconographic combinations, a new revelation or renascence of how the material could be manipulated, both physically and conceptually, developed. According to Meissen porcelain historian Ingelore Menzhausen in her assessment of Bottger's creative direction:

It is quite clear that the exacting standards of Johann Friedrich Bottger raised Meissen porcelain to the level of an art form from the very outset, and that, in addition to the manufacture of perfect table-services, he personally sought to produce works of art, or as he wrote, 'crucifixes, antique and modern bas-reliefs, as well as medallions, busts, etc.' Even in 1709, he

${ }^{19}$ Otto Walcha, Meissen Porcelain, (Putnam, New York 1981), 33. 
was stipulating that his assistants should first and foremost be sculptors. ${ }^{20}$

Depictions of hunting scenes, burlesque events, imaginative creatures, interpretations of Greek mythology, combined with the refined quality of craftsmanship, gave birth to a range of diverse works. Bottger's design plan proved to be beneficial for the studio's artistic growth and prepared a fertile creative ground on which this avant-garde work was to be made.

This diversity among artists resulted in an array of blue and white applications and interpretations combined with Persian, Italian, Japanese, and English aesthetic influences. These diverse influences can be seen on the tureen in Figure 6. First, the object itself, a tureen, is indigenously French but in this case takes on a more simple, Asian form. Second, we see references to European silver in the execution of the elegantly fluid handles. The knob is a cast figure, demonstrating Meissen's competence in casting and mold making. The decorative linear border seems to reference Persian patterns while the flowers running along the bottom of the scene allude to Japanese lacquer ware. The imagery within the outlined quatrefoil is a scene from the Chinese play the Romance of the Western Chamber and is portrayed in a deep indigo blue versus a brilliant cobalt blue (the dominate color palette in China.) The characters are engrossed in dialogue and it is left to the viewer to interpret the narrative. Finally, the whole scene contains illusory space, or linear perspective, a new sense of depth that had not yet been depicted in Asian imagery in the eighteenth century.

20 Ingelore Menzhausen, Early Meissen Porcelain in Dresden, (Thames and Hudson, New York 1990), 13. 
Meissen's interpretation of Chinese blue and white decoration, or defined in terms of European vocabulary, chinoiserie, was executed in a manner that was more geared towards the preferred taste or current trends of Europe, rather than an attempt to dissect the history or origin of the style. This means that the appeal of Chinese ceramics existed on a somewhat superficial level and that the appearance of the glaze, clay body, and color palette were more important to Meissen artists than the participation in the laborious training and discipline involved in creating the tradition of Chinese ceramics. Therefore, more concentration and effort was placed on excelling scientifically and aesthetically through the perfection of clay and glaze recipes, rather than conceptually through iconography found on Chinese export ware. The efforts of head decorator John Haroldt displayed a new-found aesthetic in trying to replicate or reference the unfamiliar territory of the Oriental world (as depicted in rugs, silks, porcelain, etc.), however the organization of iconography remained within the European lines of composition. ${ }^{21}$

Blue and white painting, as well as figurative sculpture produced at Meissen, was also used as a tool to convey narratives, to employ racial and cultural stereotypes, and to define or defend a family's name via the implementation of their coat of arms. ${ }^{22}$ Evidence of this can be seen in Figures 7-8. The strategic display of iconography seen here accomplishes a few things: first, it establishes a hierarchy within society by displaying a family's coat of arms or portrait on such a precious European commodity. Secondly, a global hierarchy is exhibited by placing people of

${ }^{21}$ Jessie McNab Dennis, "J.G. Herold and Company: The Art of Meissen Chinosoire," The Metropolitan Museum of Art Bulletin 22 (1963): 11

${ }^{22}$ Honey, 32. 
non-European heritage in subservient and submissive roles. It is possible to presume that this type of condescension and the cartoon-like display of non-white and Asian peoples sub-consciously lifted the status of European porcelain, from existing on a similar plain to Chinese porcelain ware, to a more "civilized" art form. 


\section{Chapter Two: European Taste and the Baroque Aesthetic}

It is possible to trace the lineage of Meissen porcelain works to their designers and creators; however, what remains undefined is how the fine and decorative arts of the seventeenth and eighteenth centuries informed these creations in terms of aesthetic quality and value. It is within these contexts that Meissen porcelain progressed beyond the parameters of simply copying Chinese and Japanese export ware. [Figures 9-10] The Meissen factory was in a steady line of production about five years after Bottger and Tschirnhaus' initial discovery around 1715 . For the next fifteen years the majority of the work coming out of the factory was imitation export ware, but starting in the 1730 s the work began to express its European heritage and abandoned its strong Asian influences.

The work produced at Meissen varied substantially in the first fifty years of production. However, there are specific categories of design within the Meissen genre that exemplify its transformation beyond both Asian-export copies and earlier Germanic traditions of strictly utilitarian ceramic wares. For the purpose of the historical portion of this paper, I have identified and categorized four sub-divisions of Meissen porcelain that will be examined: 1) decorative services and tableware, 2) busts, 3) monumental sculpture, and 4) figurines. These four categories represent the majority and most avant-garde work produced at Meissen in terms of the revolutionary technical and aesthetic approaches to the medium.

The first category and example of this transformation analyzed in this paper is the Meissen tea service [Figure 11] and the centerpiece for a table service [Figure 12] made for Count Burchardt Christoph von Munnich. Both sets are fundamentally 
based on the idea and traditions of function; though their aesthetic concept is based on that of spatial orientation and presentation. They are utilitarian by nature, but the intent of their makers was to activate and engage the space inhabited by the objects. The pieces' overall appearance and presentation take precedent over the basic necessity for utility, essentially form trumps function. These are not objects that are just one component in an ensemble as discussed earlier in Gillis' Breakfastpiece [Figure 5]; instead, they define the table setting. Their presence on a table demands a material cohesiveness, not to be interrupted by foreign objects or media made from glass or even stoneware. This, in turn, established a respect and reservation by the participant upon interaction with the setting.

The arrangement of both the tea service and the centerpiece is sculptural and somewhat complex in form, so to approach the service for use implies there are specific actions or roles that must be carried out for a proper experience. In other words, proper use of the service must correspond to the elegance of the piece; human behavior must conform to the same high standard as the service. The service establishes a certain type of social behavior and etiquette that in itself articulates the behavior of the elite or upper class. In the cases of this particular tea service and centerpiece this theory is feasible, for both pieces were gifts from Saxony's leaders to the courts of Russia. ${ }^{23}$

Porcelain has always been made for and used by members of the elite and those of elevated status: its production and distribution even have been controlled

23 Maureen Cassidy-Geiger, Fragile Diplomacy: Meissen Porcelain for European Courts ca. 1710-63. (Yale University Press, 2007), 68-70. 
by elite society. ${ }^{24}$ Essentially, only the wealthiest citizens were able to afford to adorn their tables with porcelain. But it was this seclusion or preciosity reserved for the material that added to the prestige and desirability of the ware. It might be presumed that the reverence held for Meissen works by the upper-class was imitated by the middle- and lower-class strata of society, who coveted both the beauty of the work and the class distinction that came with its ownership. Not only was Meissen porcelain the preferred taste, but also it was decorated and shipped to Counts and Kings of France, Italy, and parts of Germany, and ultimately dominated the market. ${ }^{25}$ Through the extreme wealth and funding of the Courts, production flourished without jeopardizing quality as there were few financial constraints.

The fact that Meissen porcelain was primarily designed for the upper class and bourgeois society implies a class distinction of those who would buy the work. These privileged or well-to-do classes were thought to have been well-educated scholastically as well as artistically, (i.e. fine arts, music, theater) or at the very least to have been exposed to such resources. Just as the participant of the table service recognizes the etiquette required for usage, so also must the service meet the standards of the class in which it is serving. Hence, a reciprocal relationship was formed and the creators and designers at Meissen were indirectly required to perform at their highest capabilities to produce work that reflected this refined relationship. Count Burchardt Christoph von Munnich's centerpiece [Figure 12] is a prime example of the way aesthetic quality triumphed over function in order for the

${ }^{24}$ Charles C. Kolb, Ceramic Ecology Revisited: The Technology and Socioeconomics of Pottery (Oxford, BAR International Series 1988), 93.

${ }^{25}$ Cassidy-Geiger, 210. 
overall presentation to be established. The functional items within the centerpiece are hardly practical: the cruets are too small to serve an entire dinner party and the sculptural elements surrounding the bowl block easy access to either retrieve or serve what was to have been contained. Essentially, the piece is a play on function.

The ownership of a Meissen porcelain cup or bowl was a signifier of upper class status, but the possession of an entire service complete with a decorative centerpiece suggests royalty. For the first time, works such as this centerpiece influenced members from the highest levels of society to view and consider ceramic ware as something other than just dinner service. These pieces became active participants in the engagement with social class. They possessed the ability to elevate the level of sophistication present at the function in which they were used and they drew parallels to the interior décor and surrounding artworks that were typically present in a distinguished household.

It is probable the designers at Meissen would have had access to works and designs of artistic significance for inspiration in order to produce an object that would surpass the level of ordinary pottery vessel. In the case of the Meissen tea service [Figure 11] the application of the gilded silver is used as a support for the ceramic pieces. The reasons for this can be interpreted in multiple ways. The silver may have been chosen to perform structurally where the porcelain may not have served. ${ }^{26}$ It is possible the ceramic designer sought to collaborate with an artist

${ }^{26}$ Although porcelain is considered to be a considerably strong and durable material, the firing processes involved with all clays ultimately limit the range of forms that are possible to be made. In the case of the tea service [Figure 13], if porcelain were to be used in place of the gilded silver, one of two things would occur: the thin, curvilinear "arms" designed to support the service would warp and disfigure during 
specializing in another trade, or perhaps the artist was influenced by a renowned work of fine art with similar intentions. German baroque art was strongly influenced by both Italian and French aesthetics and according to art critic Sacheverell Sitwell, "gave birth to works which the craftsmen of neither country working separately without the other could have produced." 27 This statement draws parallels between the Meissen tea set and works from that of Italian artists such as Cellini or possibly the decorative metalwork seen in French courts. [Figures 13-14] These relations and opportunities for exposure to art and decorative objects would have been possible for the makers at Meissen due to the heavy trade occurring between the Saxon and French courts, as well as the sweeping trends of the Italian Baroque that stretched across France and parts of Europe during the seventeenth and eighteenth centuries. ${ }^{28}$ Diplomatic gifts and trade were constantly being exchanged between Augustus the Strong and allies from France and Italy. In some cases, the workers at Meissen were encouraged to make work that was aesthetically representative of the culture for which it was being made. ${ }^{29}$ Therefore, it seems appropriate that the work from Meissen quoted the beautiful gilded

high temperature fluxing due to the thinness of the pieces, or the "arms" would have to be reinforced or thickened substantially in order to prevent warping, which would jeopardize the aesthetic quality of the overall setting.

${ }^{27}$ Sacheverell Sitwell, German Baroque Art (New York, George H. Doran Company 1928), 27, 96.

${ }^{28}$ Stefanie Walker, "The Artistic Sources and Development of Roman Baroque Decorative Arts," in Life and the Arts in the Baroque Palaces of Rome, ed. Stefanie Walker et al. (New York: Yale University Press, 1999), 3-17. (See chapter)

${ }^{29}$ Cassidy-Geiger, 141. 
surfaces created by Italian craftsman [Figures 15-16] and renowned artists like Cellini. It also makes sense that popular French art subject matter, such as Vincennes flowers, were often applied to Meissen works [Figure 17] not only to enhance the aesthetic quality of the work, but also to convey to the viewer that Meissen remained informed about the current trends of design throughout Europe. ${ }^{30}$ Sitwell also claims that "the Germans were prepared to spend much longer over their work than the Italians, and if they completed it with as much detail as the French they had at any rate designed it at the outset from a larger point of view."31

However, the second category of Meissen work, busts, may not have developed had it not been for the marvelous works of Italian sculptors and craftsmen. Under the direction of some of the sculptors employed at the factory, most notably Johann Joachim Kändler, a series of life-size porcelain busts and figurative sculptures were created. The subject matter of these busts primarily consisted of saints, papal figures and governmental rulers or crowned royalty. It is evident the Meissen sculptors were drawing inspiration from historical monuments, marble sculptures, and reliquary busts, as seen in comparison Figures 18-23. The attention to detail in the Meissen sculptors' interpretations of these works were unlike any other ceramic sculpture produced in Europe before the eighteenth century. Since Meissen was the only hard-paste porcelain producing factory during

30 The Vincennes flower was a popular French decorative element that was prolific in the design of pottery, textiles, furniture, picture frames, etc. in Parisian art markets during the Baroque and Rococo periods.

${ }^{31}$ Sitwell, 27. 
the early eighteenth century, they were the only producers of life-size or large scale works in this medium. The makers of soft-paste porcelain-sculptural works being made at Sevres and at the Saint-Cloud factory did not attempt to achieve this scale due to the technical limitations of the clay bodies. During the early eighteenth century, soft paste porcelain was thought to have been unable to withstand the pressure that the weight of a larger piece would exert and it would likely buckle or collapse during the firing process. As a result, many of the faience and soft paste porcelain factories focused on creating smaller-scale works.

A closer look at the bust of Saint Teresa [Figure 18] reveals its references to Bernini's Ecstasy of Saint Teresa (1652) [Figure 19] in the Cornaro Chapel, located in Santa Maria della Vittoria, Rome. The sculptor of the Meissen bust mimics the thrust back and tilted head posture of Bernini's well-known Saint Teresa. In bust pieces in general, there are limited opportunities to convey the full expression or content of the subject due to the constraints of being limited to only display the chest and shoulders. However, in the case of the Meissen bust, the sculptor deliberately chose to capture the distinct head tilt and ecstatic state that are immediately recognizable as elements of Bernini's design. The porcelain is left uncolored, but finished with a transparent matte glaze. The effect allows the viewer to draw parallels between the porcelain clay body and marble while simultaneously identifying the material as clay through the slight sheen of the glaze. The overall effect leaves the viewer with an alternative perception of how clay (porcelain) functions within the realm of fine art. At the very least it forced the viewer to question what materials are to be 
included or excluded within traditional definitions of fine art, and how the standard was set.

The third category, monumental sculpture, consists of works such as the model for an equestrian monument of Augustus the Strong [Figure 22]. These magnificently sculpted objects undoubtedly contributed to maintaining Meissen's notoriety. The sculpture's creator, Kändler, did not merely make the monument but portrayed the community of followers and supporters standing amongst the rubble caused by war. ${ }^{32}$ The work, standing approximately three feet tall, not only depicts the bold and ambitious king but also adds a narrative that connects him to his people- an effect characteristic of Rococo art.

The monument's lapidary character, left uninterrupted by polychrome enameling, made it comparable to sculptures in stone. ${ }^{33}$ The reference to fine art materials, such as marble and stone, in the equestrian piece by Kändler also spoke to other equestrian monuments made of other media, such as bronze. [Figure 23] The utilization of porcelain for the equestrian monument, as well as for other politically charged porcelain sculpture, also fulfilled alternative motives of the commissioner. The ordering of a piece made from porcelain, versus stone or marble, meant a rapid production rate not only for the original piece itself, but also for the production of duplicates. By the use of molds, the Meissen factory could

32 The equestrian monument sculpture was ordered by Augustus the Strong in preparation of the funerary monument that was to be constructed in his honor. The composition reflects Augustus' decisions and victories made during the numerous eighteenth-century conflicts between Saxony and Prussia, Great Britain, and even France.

${ }^{33}$ Cassidy-Geiger, 124. 
produce substantially larger quantities at a faster rate than if it were made from a more labor-intensive material such as bronze or stone. Essentially, the piece could be continually reproduced until every palace in Germany contained a copy, if so desired.

The prospect of owning a copy or duplicate of the original in this context of fine craft actually encouraged production and does not cheapen or depreciate the value of a replica. In the case of the busts of Pope V and Saint Teresa, the act of creating duplicates of personal devotional items reinforces the suitable nature of porcelain to create these life-size busts which bear sacred connotations. In addition, the mass-production methods employed by Meissen permitted a number of these replicas to be owned and displayed by people from different social classes. This brought porcelain into the interiors of people's homes where porcelain may not have previously existed.

In the examples of both the bust of Pope V [Figure 20] and the equestrian monument of Augustus the Strong [Figure 22], the sculptor, Kändler, in the case of the monument, translates stone, bronze, and silver objects into porcelain sculptures. Both porcelain works have been crafted in great detail, and capture the same spirit as their inspirations. The direction that Meissen sculptors took was one that demonstrated the factory's technological superiority amongst rival soft-paste factories, but also proclaimed the material to be appropriate for use in the creation of fine art sculpture. It is debatable whether these porcelain sculptures actually transformed the ceramic object into a fine art object, but it is reasonable to deduce 
that the creation of these sculptures certainly reinvented how ceramic objects might be perceived.

The fourth category, Meissen figurines, exemplifies the newfound placement and arrangement of ceramic objects within a domestic space. The figurines stray away from the previously discussed religious and politically charged sculpture and tend to convey the leisurely and playful spirit often associated with art from the Baroque and Rococo periods. The concept of the Meissen figurines was inspired by both Chinese Ming Dynasty porcelain statuettes and the fascinating sugar sculptures seen in French and Italian table settings. ${ }^{34}$

Johann Joachim Kändler, one of Meissen studio's most notorious sculptors and designers, was primarily responsible for the creation of the Meissen porcelain (table) figurine. Originally created to complement a table service or setting, these figures evolved and morphed into elaborate narratives responding to not only the ware but also to the social context of the group they were entertaining. The scenes displayed ranged from hunting scenes to ballets and theatrical compositions, which further enhanced the prestige and magnitude of the service, creating an interplay between the functional and sculptural pieces within a shared space.

Works such as the Crinoline Group evolved from this tradition. [Figure 24] Johann Joachim Kändler created the porcelain Crinoline Group: Musicians in 1737 at

${ }^{34}$ Michelangelo Buonorroti il Giovane, Descrizione della felicissime nozze della Christianissima Maesta Maria Regia Regina di Francia e di Navarre, Florence 1600, p. 16.

The sugar sculptures from France and Italy were deemed so impressive that at the wedding feast of Maria de' Medici and Henri IV in Florence in 1600, a replica bust of Henri IV made of sugar was present at the table setting to accommodate for his absence. 
the Meissen factory. The piece, sculpted in the round, consists of three primary components: the man and woman musicians and the settee upon which they sit. Made of porcelain, the piece emulates and evokes the character of marble, with its crisp, sharply executed drapery and entirely white color palette. The meticulous rendering and ornate detailing of the figures, instruments, and settee, paired with the sophistication of its marble-like appearance allows the object to transcend being perceived as merely a craft object and reinvents the ceramic figurine as a fine art sculpture.

The word "crinoline," refers to the undergarment structure used to keep a woman's dress in a specific shape and immediately implies an elite lady, a member of upper class society, since servants and women of the lower class could not function properly in such garb. Her elaborate dress flows out onto the settee and swings over to the floor in a manner that implies arrested movement even though she is sitting. She plucks her instrument and her gaze is fixed upon her male counterpart who plays the flute, seated in an upright posture, his legs separated and one boot tip lifted off the ground as if he is tapping along to the melody. He, too, is dressed elegantly in an elaborate coat, knee breeches, and boots with buckles. Kändler's design informs the viewer of how these types of clothing lay and fit on the body, expressing a fashionable elegance that adds a sense of idealism to the work, allowing the eighteenth-century viewer immediately to engage with the piece. This observation is important in establishing what the piece implies: a carefree, wealthy and well-dressed couple, perhaps from court, playing music, enjoying the moment 
and celebrating, qualities congruent with the Rococo era during which it was created.

It is important to recognize what Kändler does with the clay and how his methods function within the work. There are three major components that make up separate textures executed in the work: the drapery of the clothing, the figures' skin or flesh, and the detailing of the chair or bench. Kändler sculpts the dress with deep undercutting, overlaps and creases, which mimics the fabric or drapery seen in Greek and Roman marble sculptures dating back as far as the fifth century B.C.E. Aiding in this comparison is Kändler's implementation of the facial features, especially the "blank eye," which borrows from marble sculptures that had painted eyes dating back to Antiquity. The chair detail is a revelation! The ornate, curvilinear qualities of Baroque furniture are extraordinarily molded followed by the application of the cast details added to the form. This is very similar to the practices of actual woodworking and furniture making in which a separate piece is made and then added to the base form.

Finally, the piece reflects contemporary European milieu; it is not conceptually tied to religious statuettes from China or transient sugar sculpture from France or Italy. Rather, its intent is to reference fine art while simultaneously being an accessible commodity for upper class society. The decision to make the piece from a clear-glazed, buff-white porcelain and to not add color articulates an elegance and refinement of the material, strongly referencing the much-respected and revered marble. In some cases, the porcelain does things marble cannot do, as 
parts of the object are created separately then fused onto the chair in the firing process, allowing for vast spaces and complex undercuts to exist.

The breadth and versatility of objects that Meissen produced in its first fifty years of production encompassed iconographic content of both the fine and decorative arts. Suddenly, there was a material that could achieve new heights in artistic achievement. The attention to form and presentation of the exquisite tea services and centerpieces nodded to high-society taste and extravagant interior décor. These wares possessed the power to inform social behavior and initiate ceremonial protocol through their presence on a dining table. The sculptural works created by Kändler and his fellow sculptors at Meissen embraced the integrity of fine art materials such as stone, marble, and bronze and applied their interpretations through porcelain media. This resulted in the creation of ornately detailed and narrative-inspired works that surpassed the level at which any other competing porcelain studio at that time was able to perform.

By the mid-eighteenth century the Meissen factory was in competition with approximately twenty-five porcelain-producing studios throughout England, France, and Germany. ${ }^{35}$ This was due to the massive leaking of Meissen's recipe through former-employees hoping to receive monetary compensation in exchange for the secret recipe. In spite of this, Meissen maintained its reputation as the most versatile, important, and most adventurous of all the European porcelain-producing factories. ${ }^{36}$ Aiding this reputation were the technological innovations of clay, glaze,

35 Walcha, 160.

36 Walcha, 160. 
and slip recipes at the Meissen factory. This freed the artists from the constraints and limitations of clay materials formerly in use.

Ehrenfried Walther von Tschirnhaus was famous for his expertise and knowledge of natural history, physics, and mathematics, and Johann Bottger, a brilliant young alchemist, was thought to harbor the knowledge of transmutation: the ability to transform inexpensive materials into gold. ${ }^{37}$ The contributions and breakthroughs made by these men were entirely interdependent on both men's knowledge and innovations. It was the combination of Tschirnhaus's invention of large "burning glasses, or lenses," that created an intense concentration of solar heat within a furnace allowing various flux tests to be performed, and Bottger's invention of adding the precise ratios of alabaster (calcium sulfate) and a local, iron-free white clay, that allowed this European porcelain to be created. ${ }^{38}$

Their clay composition withstood the extreme stress it was subjected to from the sheer weight of the objects and was less susceptible to warping or disfigurement due to a slower firing process. This technology allowed the artists to become more bold and confident with the material. This in turn allowed them to focus more on the formal qualities of the work, versus the limited capabilities of other clay body compositions.

37 Walcha, 15.

W.D. Kingery, "The Development of European porcelain, "Technology and Style 3 (1986), 162.

${ }^{38}$ W.D. Kingery, “Development,” 164. 
The evidence of this technological superiority can be seen upon close examination of Meissen porcelain's surfaces and forms. When compared with early to mid-eighteenth century soft paste porcelain works from France and Italy, Meissen porcelain, from this same time period, exhibits an apparent aesthetic progression towards accelerated clarity and superior quality. ${ }^{39}$ For Meissen porcelain to overtake the already established soft paste porcelain markets and factories, such as Saint-Cloud and Rouen, its wares would have to be impeccable. Even though the art of soft paste porcelain, or frit porcelain (pâte-tendre), had been manufactured since the year 1673, approximately thirty-seven years before the discovery at Meissen, in Rouen, France, the inferiority of the material is evident. Italian versions of the frit porcelain date back as early as 1519 , but exist sporadically and in such small quantity that it is hardly fair to compare its quality with that from a porcelain powerhouse such as Meissen. ${ }^{40}$ It is to this statement that the focus of this comparison between European soft paste and hard paste porcelain shall remain between France and Germany respectively, for these two countries represent each genre of early to mid-eighteenth century porcelain most accurately.

The purpose of this analysis is not to discredit the innovations of French soft paste porcelain factories, for a significant space in ceramic art history is reserved for the work produced throughout France in the seventeenth and eighteenth centuries.

${ }^{39}$ This statement transpires from the observation and study of the porcelain objects produced from the factories at Meissen, Saint-Cloud, Venice, and sections of England displayed in the Decorative Arts department at the Metropolitan Museum of Art in New York.

${ }^{40}$ Edwin Atlee Barber, Artificial Soft Paste Porcelain, (New York: Doubleday, Page \& Company 1907), 57. 
However, there are definite reasons as to why and how this work fell short in terms of technological and aesthetic excellence. First, upon close examination of the surface quality of both wares, the clarity of Meissen's clay body is evident because of its crisp, cool, and stark-white quality versus the warmer, more cream-toned white surface of the soft paste porcelain. The underlying hue of the porcelain has a substantial effect on the appearance of glaze applied to its surface. It is common knowledge that color appears more brilliant or saturated when applied to a white ground versus an off-white ground. While this statement is relevant to mediums involved in painting and printmaking, it is also a core component of a work's identity within the realm of ceramic media. Unlike painting or printmaking, where additional processes can be added indefinitely, there is a point at which the nature of the material in ceramic art will no longer physically accept more pigment or glaze. In other words, there is no way to increase a color palette's brightness on a work of ceramic art after it has been fired unless one is to do so artificially with topical paint- consequently making the shade or hue of the porcelain itself a vital characteristic. ${ }^{41}$

The whiteness of Meissen's porcelain body allows for glazes to appear more vivid. The resulting colors emerge more boldly and confidently from the form. This attribute, paired with the experienced brushwork applied on Meissen works, allows

${ }^{41}$ For the purposes of this discussion, white slips and engobes are considered irrelevant. Although the technology of this whitening procedure was widely-known and available by the eighteenth century, neither factory employed the use of these whitening agents in their production. This validates that the decision made by the artists of French soft-paste porcelain to maintain the integrity of an off-white clay body was indeed both conscious and intentional. 
the surface decoration to activate and enliven the form it encompasses, whereas the surfaces of French soft paste porcelain works seem to exist superficially as if the glaze is not truly bound to the surface. Furthermore, the composition of French soft-paste porcelain meant it could not be formed or sculpted thinly; thinness is an essential characteristic of both Meissen and Chinese porcelain. According to archaeologist Edwin Atlee Barber on the subject of soft paste porcelain composition:

When the material is made thin and fired, pyrophanous or mechanical defects in the form of translucent discs, known as "pin points" or "grease spots" caused by vitreous particles in the paste and imperfect blending of the ingredients...So characteristic are these translucid spots, in size and distribution, that they frequently furnish the only means of identifying the products of certain factories to those who have made a special study of them. ${ }^{42}$

These compositional imperfections of soft paste porcelain inhibited the French work from producing any threat to the success and popularity of Meissen porcelain. In terms of formal qualities of both wares, it would be inaccurate to distribute full credit to Meissen for their visual concepts. There was a great deal of aesthetic borrowing between Meissen and the Saint-Cloud and Rouen factories. Nonetheless, French soft paste porcelain could not overcome the inferiority of the deficiencies found in its compositional makeup. The forms produced by Meissen are unscathed by similar deficiencies and prove to be superior in both execution and composition, as has been outlined in this paper.

${ }^{42}$ Barber, 23. 


\section{Chapter Three: Impact and Expansion}

The popularity and dominance of the Meissen aesthetic flourished throughout the eighteenth and nineteenth centuries during which time there was support and a market for mass production of the ware. Logically, mass production leads to mass exposure, and the work produced at Meissen expanded both conceptually and geographically, affecting ceramic artists and factory design alike. Although considered "a naturally evil product of an idle and vicious society," by Arts and Crafts advocate John Ruskin, the Baroque and Rococo art movements contrarily provided a fertile and stable environment for the art of ceramic porcelain ware to expand. ${ }^{43}$ With influence already coming from Asia concerning tea rituals, the factory produced associated ceramic accoutrement. In addition, an array of item specific wares poured out of the Meissen studio: snuff boxes, mantelpiece clocks, needle cases, cane handles, etc. All of these new objects combine as an ode to an emotive, whimsical attitude as they pay respect to this new found material, exploring and testing its structural and conceptual boundaries.

In accordance with Bottger's mission statement, over two hundred different models of service and service-related items were in production at the Meissen studios within the first twenty years of its opening. ${ }^{44}$ In addition to the excitement and passion applied to this new artistic awakening, the vast majority of dinnerware produced by Meissen was to be displayed and organized in sets, or services. Never before in history had such thought, specificity, and cohesiveness been brought to a

\footnotetext{
43 Honey, 12.

44 Cassidy-Geiger, 67.
} 
table setting. This elaboration of function inspired subsequent centuries of ceramic artists' celebration of utilitarian pottery. It is the fortunate compilation of a newfound ceramic material, individual and original artistic direction, unrestricted funds, and support from European courts that allowed Meissen porcelain works to be transported into a new realm, one that has pushed boundaries and established new ideals for the material, ultimately inspiring centuries of movements in ceramic art. This undertaking to examine and produce work of such diversity and original creativity is something even twenty-first-century ceramic artists seek. In a sense, Meissen opened the doors of possibility and freedom to explore new techniques, cultures, and aesthetic sensibilities. From an artist's perspective, the work made it acceptable to select visual components and characteristics from foreign cultures' aesthetics and allowed the artist to construct an individual interpretation of these qualities. The Meissen artists began to combine disparate elements in the creation of their porcelain works.

The impact Meissen porcelain has had on ceramic art is still felt today. Its artistic legacy has been copied, referenced, reinterpreted, and dissected by contemporary ceramic artists. The studio methods and techniques that originated at Meissen remain some of the most influential processes utilized by diverse ceramic artists working both in traditional and non-traditional media. Some references are visual or based on form, as seen in the work of contemporary artist Kristin Kieffer. [Figure 25] Her piece, Flower Vessel, suggests influence from Baroque and Rococo elements and strongly references the Meissen gothic prototype in Figure 26. Kieffer's vessel takes the original idea of the design and adds an elegant 
and subtle surface design and modern color palette choice. Her exaggeration of the basic Meissen form alludes to her interpretation of this type of work.

The Meissen studio was also the innovator of large or even life-scale porcelain animal figure. Animals ranged from the exotic to the domestic: monkeys, camels, goats, dogs, felines, etc. Almost all figures were unpainted, and some were even left unglazed, resulting in an absolutely white figure of relatively large scale. [Figure 27] The peculiar choice of animals paired with odd body juxtapositions and facial expressions is echoed by contemporary artist Beth Cavener Stichter, whose work also represents the odd and unusual placement of animals and their body positions. [Figure 28] The artist's work takes on a darker interpretation of these animals, but once again, it is interesting to examine the similar qualities in these two works differing in a time span of more than two hundred years.

There are also more subtle contemporary references as seen in Silvie Granatelli's swan handled pitcher, and the swan handled piece coming from the Meissen factory in the mid eighteenth century. [Figures 29-30] Granatelli's pitchers are much more modern and minimalistic, but the spout execution, along with the graceful application of the swan handle, reference the Meissen piece to a noteworthy degree. While much of Beth Lipman's work is in mixed media, it speaks to the elaborate porcelain table settings that dominated upper-class societies' interiors in Germany and the rest of Europe during the eighteenth and nineteenth centuries. [Figure 31] Her work reflects the specificity of objects and strong sense of placement similar to many of the services coming out of Meissen. Some of these contemporary references are subtler than others, but all are tied by a similar theme; 
the sense of delicacy, refinement, attention to detail, and elegance. The Meissen aesthetic has influenced artists both technically and aesthetically, some testing the physical boundaries of porcelain, others strictly referencing the visual qualities of the work.

Meissen works are also highly valued and sought after within great collections of fine art. They reside in auction houses such as Christie's and Sotheby's, with collectors paying exorbitant prices to possess them. They are also found in major art museums, conservation labs, private collections and antique markets. Whole museums exist for their exhibition, as seen in the Maridon museum located near Pittsburgh, PA. This paper has established that Meissen works are something valuable and should be harbored and protected. The question is, what efforts have been and are currently being made to preserve this work? Have antiquated restoration techniques damaged, enhanced, or had no effect on Meissen porcelain pieces? And when does the restoration process in and of itself become separate from the object and an important part of conservation history?

Since Meissen porcelain is a line of work so steeped in precision and presentation, it is worthwhile to examine these conservation processes, both antiquated and recent, to observe the effects they have had both aesthetically and structurally on the work. Considering the historical, artistic, and technological significance of Meissen porcelain as analyzed in this paper, and its impact on ceramic art history, special considerations must be taken into account during conservation practices to ensure the work maintains its integrity. The three separate case studies to be analyzed in this paper involve the practices of ceramic 
riveting, object replacement and material substitution, and a condition assessment report for the Fürstenzug mural in Dresden, Germany. These have been selected for very specific, intentional reasons. The methods applied (or lack of methods applied) to these works bear the most visually-intrusive and structurally-jeopardizing effects. The purpose of outlining these particular situations is to demonstrate the necessity or relevance of revisiting and revising previously-applied conservation procedures on Meissen porcelain. 


\section{Case Study 1: Ceramic Riveting/Stapling}

A certain threshold seems to exist in the conservation of ceramic objects in terms of the level of damage exposed or deterioration left apparent by the conservator. It seems the conservation of archaic ceramics is approached and treated in a different manner than antique ceramics, such as Meissen porcelain. ${ }^{45}$ Different expectations concerning the appearance of the work, both by public audiences and museum professionals, guide a certain standard or protocol concerning the object's appearance. In a museum setting, it is quite acceptable and common to see the patched surfaces of Early Jomon or Native American ceramic artwork with some sort of apparent synthetic fill or epoxy. Is this because one expects to recognize the material's degradation and "age" because of its historical context?

According to the American Institute for the Conservation of Artistic and Historic Works' Code of Ethics, it is the responsibility of the conservator that he/she assigns an appropriate treatment protocol that is entirely reversible and that does not falsify the aesthetic, conceptual, and physical characteristics of the work in question. This code firmly states:

The conservation professional is responsible for choosing materials and methods appropriate to the objectives of each specific treatment and consistent with currently accepted practice. The advantages of the materials and methods chosen

45 The term archaic ceramics in this discussion pertains to ceramic works produced within a certain time frame prior to the existence of an industrial society. For example, these would include works from Ancient Greece/Rome, Egypt, certain Mayan and Native American cultures, and ancient Asiatic cultures, in addition to other ancient civilizations. The term antique ceramics typically relates to ceramic works produced in Western post-industrial societies, and are relatively new, ranging anywhere from around seventy-five to three hundred years of age. 
must be balanced against their potential adverse effects on future examination, scientific investigation, treatment, and function.

Any intervention to compensate for loss should be documented in treatment records and reports and should be detectable by common examination methods. Such compensation should be reversible and should not falsely modify the known aesthetic, conceptual, and physical characteristics of the cultural property, especially by removing or obscuring original material. 46

These rules of conduct are what dictate the majority of restoration work done for museum-designated pieces. In particular, they are what inform the preferred route of restoration. In the case of archaic versus antique ceramics, the Code of Ethics provides justification for the apparent patched surfaces of so-called archaic or archaeological pottery in the reasoning that the conservator does not obtain the right to assume the entirety of a work dating back beyond a certain time period. This specific type, or style, of conservation is regarded as archaeological restoration and is often used for publication purposes to date the actual site. ${ }^{47}$ The same procedure is then carried over to more "archaeological related" museum pieces, such as Native American artifacts or Ancient Greek ceramic vessels. The necessity for this type of aggressive restoration procedure is due to the likelihood that these archaic wares will be found in a series of shards and fragments that will need to be pieced back together. The porosity and unvitrified surfaces of many of these archaic

46 "Code of Ethics and Guidelines for Practice," American Institute for Conservation of Historic and Artistic Works website, revised August, 1994, accessed February 14, 2011, http://www.conservationus.org/index.cfm?fuseaction=page.viewpage\&pageid=1026.

${ }^{47}$ Michael Belman, Objects Conservator at Carnegie Art Museum, personal interview by author, February 11, 2011. 
clay bodies weaken their overall composition and longevity, also contributing to the need for this type of restoration. But how do these obvious patchworked methodologies and visually obtrusive restorative processes affect a ceramic work that is not as dated or severely deteriorated and whose material composition is quite different and substantially more resilient- like that of Meissen porcelain?

Unlike materials and media such as paper, paint and ink, fired ceramic material is not degenerative- it does not fade or tarnish, and it does not chemically break down over time. When mishandled, it will break, chip, scratch, or crack, which results in generally superficial or surface repairs. One of the oldest and most recognizable treatments for surface repairs on ceramic material is the art of stapling, or riveting. There is open debate about exactly when and where the act of applying lead or metal rivets to ceramic media originated. Earthenware artifacts have been excavated in the Middle East and Europe dating from 7000 B.C.E. showing evidence of repairs made from various glues and plasters, as well as from lead and iron rivets. ${ }^{48}$ However, the procedure of riveting is most widely known through its excessive applications by Chinese "riveters." The process was so heavily used in Chinese porcelain that the term "China mender" seems to encompass all persons involved internationally in the restoration of pottery objects throughout the eighteenth and nineteenth centuries.

The distinct quality of these iron rivets and their contrast to the pure white clay have adorned Chinese porcelain objects for centuries and continue to do so

48 Isabella Garachon, "From Mender to Restorer: Some Aspects of the History of Ceramic Repair," Glass and Ceramics Conservation 2010, Interim Meeting of the ICOM-CC Working Group, Corning, New York, Oct. 3-6, 2010, ed. Hannelore Roemich: pp. 23. 
today. [Figure 32] The primary basis of this type of restoration procedure is to restore and meet the fundamental need for utility concerning the object of interest. Up until recently, natural glues and adhesives proved to be incompetent in fulfilling this requirement. This is due to the role ceramic vessels employ during typical domestic use; the object needs to be able to hold water and be heat resistant, which are two primary characteristics of utilitarian pottery. Where natural glues and adhesives fell short of these qualities, durable metal staples proved to be proficient in satisfying these requirements. This is largely due to the nature of porcelain clays' composition. Fired porcelain clay is completely vitrified and watertight with a smooth, glassy surface. When it breaks, it leaves no toothed or rigid surface to which these natural glues and adhesives can be sufficiently secured. This, along with the non-porous quality of its clay matrix, made porcelain objects unlikely candidates for successful glue-based restorations. Metal rivets, however, function as a clamp that securely holds the constituent pieces together, ultimately providing the most secure connections possible for ceramic restorations done from the eighteenth through early twentieth centuries.

The procedure for applying metal rivets or staples to ceramic ware is relatively straightforward in theory; however, the restorer's level of mastery and dexterity are crucial to a successful restoration. Holes are drilled either partly or entirely through the ware, depending on whether a partial or "all the way through" staple is necessary to fully stabilize the object. ${ }^{49}$ This factor is dependent upon the

${ }^{49}$ See J. Howorth's, The Art of Repairing and Riveting Glass, China, and Earthenware... (Aberdeen University Press 1900): 10-33. 
thickness or thinness of the clay walls and the overall fragility of the object. In the eighteenth through twentieth centuries the restorer, or "China mender," assumed responsibility for bearing knowledge of various clay bodies and their compositions as well as demonstrating expertise in their craft of stapling and mending. The role of the ceramic restorer today seems to have evolved from the profession of artist or tradesperson repairer to the realm of scientific analyses and study. This progression, began sometime around the fifteenth century in Europe and correlates with both societal advancements in technology and science as well as the occurrence of cultures' need to conserve and display ceramic objects in an attempt to preserve a link with their heritage or history.

Interestingly, the term "riveting" does not solely pertain to ceramic stapling. ${ }^{50}$ It also encompasses procedures involving lacing, binding, and tyingwhich do not consist of applying staples to a ware. These alternative methods involve the lacing together of porcelain through bored holes with metal wire (similar to tying a shoe lace) and tightened as a tourniquet would be, and are visible on both sides of the porcelain. Alternatively, binding and tying are processes that do not involve the boring of holes; instead, a copper wire is used in a superficial technique that literally "ties" the surface together externally. While all three alternative methods are sufficient in stabilizing a defected ware, none are as visually minimally invasive as ceramic stapling, which provides the least aesthetically obstructive procedure. This reasoning provides the grounds for ceramic stapling to

${ }^{50}$ Claudia Sydney Maria Parsons, China Mending and Restoration (Faber \& Faber Ltd. 1963): 28. 
be the preferred method of porcelain restoration and is also what is most commonly seen in wares displayed in a public setting.

The act of displaying a historical ceramic object within a public museum or gallery setting removes the piece from its original context. The utility requirements of the object are no longer a primary issue and as a result, focus is redirected to the aesthetic qualities of the work. In the event that a ceramic piece is covered in rivets, there are several consequences that may occur. First, the foreign metal material interrupts the aesthetic quality of the piece. The rivets break the visual cohesiveness of the object and as a result can become the focal point in some instances. However, the rivets also signify the importance of the piece and that the object itself was worth undergoing the laborious restoration treatment in order to be preserved.

From the journals of Matthew Ricci that date back to the sixteenth century, Chinese culture had mended or "sewn" back together porcelain objects not only to preserve their utility but also to preserve their artistic and cultural integrityessentially declaring the porcelain object as an item worth repair. ${ }^{51}$ Secondly, the riveting or stapling in and of itself becomes a part of conservation history. The processes can then be analyzed and studied, ultimately providing valuable information concerning the history of ceramic restorative processes. This in turn helps conservators understand the different techniques of riveting, why they were used in a particular situation, and how the restoration was either successful or unsuccessful in its purpose. Thirdly, the placement of rivets on a ceramic work can

${ }^{51}$ Louis J. Gallagher, S.J. (Translated from Latin by) China in the Sixteenth Century: The Journals of Matthew Ricci: 1583-1610 (Random House 1953): 15. 
dictate the piece's value or worth, both monetarily and historically, and ultimately contribute to the object's destiny in terms of its locale or placement. The Meissen serving dish [Figures 33-34] offers a prime example, exhibiting how the previously mentioned repercussions of riveting can affect the context of a ceramic work. For the purposes of this paper, this serving dish will be the primary example aiding in the analysis of riveting in Meissen porcelain.

The serving dish belongs to a line known as the Blue Onion pattern series that was initially produced by Meissen in the eighteenth century. The series was influenced by blue and white designs from Chinese Ming Dynasty wares in the fifteenth century. The series primarily consists of a white background (i.e. the bare porcelain) and blue brushwork with varying concentrations of cobalt oxide. The Blue Onion design consists of Baroque-inspired asymmetrical, curvilinear floral patterns that occupy the center portion on plates and serving dishes, and that circumscribe the surfaces of teacups and saucers. The rims of plates and serving dishes from this line are typically scalloped and indented, as well as sometimes having a latticed rim. The obverse of the dish is typically left without any decoration, aside from the artist's signature. These "signatures" vary substantially [Figure 35] and serve as a primary means for assisting historians in the accurate identification of the ware and in connecting the piece to its creator and time period. ${ }^{52}$ As for the Meissen dish in Figure 33, the signature consists of the crossed double sword, which is indicative of the signature of Johann Gregor Höroldt (1696-

52 Linden Heitland, "Old Meissen Porcelain: Its History and Decoration," The Connoisseur 22 (1908): 90-92. 
1775), the factory's chief painter from 1720 to around 1770.53 The dates of Höroldt's employment at the factory accurately coincide with the creation or occurrence of the Blue Onion pattern, which has been dated back to approximately 1739.54 Thus, the serving dish can be roughly dated to the thirty-one year span from $1739-1770$.

Through the general knowledge obtained concerning the overall age of the serving dish, it is possible to hypothesize and determine the tools or machinery utilized in the production of the piece, as well as the compositional formulas of the pigments and enamels applied during the specific time period. Upon close examination of the Meissen serving dish, two features are apparent. First, it appears the dish was made from some type of ceramic press due to the form's convex outline or base shape. In other words, there are no undercuts or places where the dish would become trapped or stuck within a mold or press. This design attribute is characteristic of ceramic work approached from a mechanical standpoint versus a strictly hand-crafted methodology. This information reveals that most likely the particle dispersion throughout the clay is relatively even and consistent due to the extreme compressive strength these ceramic presses possess- allowing for increased structural stability and integrity within the piece.

53 Johann Gregor Höroldt was one of Meissen's most skilled and influential porcelain decorators ever to be employed at the factory. He is known for his close study of Chinese and Japanese ceramic design, innovative brushwork techniques and also for the development of original enamels and glazes used in the ware under his direction. Over fifteen of Höroldt's enamel colors remain the composition that is still used in porcelain decoration today.

${ }^{54}$ Jim Harran and Susan Harran, Meissen Porcelain: Identification and Value Guide (Schroeder Publishing 2007), 139. 
The second feature apparent upon close examination of the serving dish is that the holes puncturing the rim that create the lattice effect were indeed hand-cut and executed pre-firing, at the clay's leather hard stage. The knife marks surrounding each individual gap paired with the inconsistencies of the holes' shapes provide proof that the punctures were handmade with some sort of scalpel or knife versus a piece of machinery. The cuts are sharp and precise and the clay does not buckle or give way to the pressure of the tool used, suggesting the clay was quite hard during the procedure. These general assessments contribute to the overall knowledge of the piece's technical process and material culture. Ultimately, this supplies initial information for the conservator about the possible origin of the defect and the restorative efforts previously applied.

Interestingly, the defect on the Meissen serving dish example is a curved, three-inch crack on the indented section of the rim that does not expand onto the latticed section, an area where one might anticipate the crack to extend. It has been repaired with three brass staples ranging somewhere between the 16-17 gauge size and has been painted over with paint or resin. It appears the two outside staples have fully penetrated through the clay walls whereas the center staple does not. Evidence of this is seen through the ground plaster or cement and buffed, unglazed circular areas on the front of the dish, suggesting that more support was necessary on the exterior sides of the crack. Depending on when the restoration was performed, the compound applied over the restoration could be a type of cement or adhesive used to further secure or stabilize the rivets, or it could merely be a cosmetic paint used to reduce the staples' visibility. Further testing through formal 
chemical analyses would be necessary to reveal the compositional components and complete extent of the materials used in the restoration. ${ }^{55}$

The restoration applied to the Meissen dish, whether deemed appropriate or not, suggests the piece was worth repairing to some party involved. The piece does not evince the characteristics of being an independent or solo work. Instead, it presumably was restored because it belonged to part of a set or service, as did most of the Blue Onion series created by Meissen. The monetary and culturally historical value of the dish has been substantially minimized when compared to other pieces from the series. This is most likely because of the restoration process applied. This is not to say that stapled or riveted pieces do not exist in museum or gallery settings, because there is evidence proving the contrary, as seen in major collections in museums such as the Freer \& Sackler Galleries and the Metropolitan Museum of Art.

However, it is a noteworthy observation that the majority of these stapled clay objects on display are considerably older in age (pre-fifteenth century) and are also primarily artifacts from Asian cultures. This association creates an interesting stereotype that seems to justify riveted ceramic work in a museum or gallery setting because of the object's age and culture. Ceramic stapling is conceptually and indigenously an Asiatic procedure and it is debatable whether its associated history actually pads or lessens the severity of visual disconnect between the foreign metal material on the porcelain. However, the cultural connection between the

55 Nigel Williams', Porcelain: Repair and Restoration (University of Pennsylvania Press 1983) 28-40.

The use of ultraviolet illumination, a binocular microscope, and/or an X-ray scan will help further aid in the identification and analysis of the severity of the previous restoration and its components. These tools provide a viewpoint that would otherwise not be accessible or apparent from an initial or basic observation. 
historically Asian stapling and porcelain does seem to broaden or add depth to Chinese art and historical objects, making it more acceptable or appropriate to publicly display the stitched ceramic vessels.

This theory suggests that the context of the piece informs conservation protocol. As for the museum display of non-Asiatic riveted wares, the same cannot be said about any type of European porcelaneous clay body- especially Meissen porcelain. This restoration procedure essentially condemns afflicted works to a life in second-hand antique shops and lower end auction houses. It is out of the question for any type of riveted or stapled European porcelain to be bought or sold at establishments such as Christie's or Sotheby's.

For instance, in June of 2005, a pair of sculpted herons (in excellent condition) from Meissen's own Johann Joachim Kändler sold at a Christie's auction in Paris for an estimated 6.8 million USD, ultimately setting the world auction record for European ceramic art. 56 This case in point validates the notion that works produced at Meissen are historically and artistically significant and still to this day exist as a precious commodity. Alternatively, the Meissen Blue Onion serving dish sold for approximately 40 USD, creating quite a price differentiation between the two works. Obviously there are other factors aiding in this drastic price discrepancy, including the historical and political significance attached to the herons, so to only use this extreme case is not completely accurate. The fact remains that other Meissen Blue Onion platters and dishes (none of which have

56 Rebecca Knapp Adams, "White-Hot Wares," Art Info website, http://www.artinfo.com/news/story/28359/white-hot-wares/ accessed $01 / 25 / 2011$. 
been damaged and stapled) are indeed being represented in galleries and museums alike and are being sold for prices ranging in the thousands in antique and art auction houses.

The primary concern with the stapling of Meissen porcelain is that the procedure creates such a vast disconnect between the technical genius of the porcelain material itself and the somewhat archaic and crude methodology applied. The technology achieved by the makers of this porcelain and its compositional superiority remains far more advanced than the restoration procedure applied. Furthermore, the cultural and historical association of the indigenously Asian procedure seems to inhibit the basic fundamental purpose of European hard paste porcelain, which was to exist independently (both aesthetically and technologically) from China's porcelain industry.

The debate of whether or not to proceed with additional restoration processes in order to diminish, or possibly eliminate the appearance of the staples, is an issue between conservator and curator or owner. If the repaired piece and the restoration are in good condition and there is no evidence of discoloring or instability surrounding the rivets, then technically the piece is stabilized and no further processes should be applied. However, if the aesthetics of the restoration are unappealing or unwanted and prove to jeopardize the stability of the ware, it is possible to remove the rivets and treat the object with a more contemporary and perhaps more suitable process. Depending on the compressive strength of the rivet, 
it may be removed by hand or may need pliers to snap out the staple. ${ }^{57}$ Once the rivet is removed the area would need to be treated with a number of solvents to remove any dirt or debris as well as any previous cements used in the initial restoration. Alternatively, it is possible to leave the staples intact but minimize their appearance by grinding and buffing down their surfaces. This would allow the internal structural support to be maintained while minimizing the rivets' visual obstruction. Lastly, the object is to be treated accordingly to the conservator, curator, or owner's needs.

In the event of restoring the Meissen Blue Onion platter to its fullest potential, procedures extending beyond the parameters of simply dealing with the riveting must be taken into account. If it is requested that the rivets be removed, a suitable adhesive must be applied, such as Paraloid B 72, to connect the broken pieces. Paraloid B 72 is a thermoplastic acrylic resin that has proven to be sufficient in the binding of glass and ceramic objects as well as in other media such as wood and canvas. In addition, the resin is considered a reversible material in that it is soluble in both Toluene and Acetone, fulfilling the American Institute for Conservation's Code of Ethics reversibility requirement for a treatment plan. This type of technologically advanced material far surpasses what would have been available in terms of adhesives during the eighteenth and nineteenth centuries, including animal protein-based and casein glues.

57 Claudia Sydney Maria Parsons, China Mending and Restoration (Faber \& Faber Ltd. 1963): 69. 
Next, an assessment and treatment of the surface's losses is necessary. Traditionally, plaster would be the primary medium used to fill any losses. Plaster is still considered a valid material for this procedure; however, cellulose fillers such as Polyfilla or Polyfix, in addition to kneadable epoxy putties, seem to be the preferred materials. The most challenging part of this procedure is not the resculpting process of the missing profile information. Instead, the difficulty lies within the matching of the specific hue of white in the porcelain, which can take a great deal of trial and error before achieving the precise shade or color. ${ }^{58}$

The last issue needing to be addressed on the Blue Onion platter is the missing cobalt paint decoration and design. This is where an individual conservator's interpretation and opinion of how the object should be finished comes into play. As previously mentioned, the American Institute for Conservation's Code of Ethics states that in no way should visual information be falsified or misrepresented during the treatment of an artwork or artifact. Essentially what this is conveying is that no additional information or processes should be applied to preexisting properties in stable condition. The trouble with this concept is that it is difficult to accurately (or believably) mimic a brushstroke when having to do so in a constricted area without crossing over into the stabilized section of the piece. This has the potential to result in an obvious inpainting job that lacks the fluidity of the original design. This is where some conservators choose to employ tactics that focus more on creating a cohesive, fluid finalized piece that is visually more akin to its original prototype rather than executing a restoration in which the brushwork is

${ }^{58}$ Belman, Interview, February 11, 2011. 
purposely made apparent. This decision involves a technique that blends both preexisting and newly applied information to create a homogenous effect that harbors a smoother transition from old to new.

Realistically, the need to re-work a riveted Meissen piece must be determined on a case-by-case basis due to the sheer number of objects that would need to be addressed as well as the overall number of ceramic objects waiting to receive their initial conservation plans. The amount of work required to completely remedy this dilemma would be costly and lengthy, not to mention somewhat illogical. Unlike Meissen's Fürstenzug Mural (discussed in Case Study Three) the components of Meissen porcelain tableware may be desired as a cohesive unit, but ultimately are not physically bound to do so. Whereas the mural relies on the unity of its constituent pieces in order to function both aesthetically and structurally, tableware components are able to physically exist independently. It is for this reason that not every improperly or imperfectly restored Meissen piece needs to be re-worked, although it may be preferred. 


\section{Case Study 2: Material Substitution/Object Replacement}

Material substitution and total object replacement are similar processes that coexist in the same subcategory of ceramic restoration. These two terms cover the broad spectrum of situations that have occurred in the treatment of damaged ceramic media. Referring specifically to ceramic restoration, material substitution encompasses all non-ceramic media applied to a ware. The restorer's primary intent may have been to compensate for a section of total loss, reinforce a structural instability within the ceramic work, or to restore the basic functionality or utility of the object. Many times the foreign material is applied in a manner that blends with or mimics the original surface. The implementation of object replacement bears the same initial goals as material substitution, but focuses more on restoring the optimal aesthetic integrity of the object. Many times an entire spout or handle has been replaced not only with the intention of restoring function but also to demonstrate the artistry of another craft. [Figure 36] The restorative processes applied in this procedure may be, but are not limited to, non-ceramic media as defined in material substitution; they include metals, clay, plaster, wood, epoxies, and resins. It appears the fundamental difference between the two terms is that material substitution is used to salvage and preserve as much original ceramic material as possible whereas total object replacement eliminates the defective area and replaces it with an entirely new component.

Ultimately, the applications of both material substitution and object replacement to a ceramic object work in unison to stabilize and restore the piece. The combination of both foreign material and original clay media applications are 
what make these restorations function. Although the methods, media, and even the identification of the restorer involved in these processes vary substantially, their utilization was a result of damaged ceramic ware of substantial value and stature. The variety and diversity of materials and methods within both material substitution and object replacement make it difficult to generalize the overall processes involved. To analyze this type of restorative procedure and its relationship to Meissen porcelain, different examples of independent situations will be assessed.

Similar to the process of ceramic riveting, the implementation of both material substitution and object replacement assign an importance or value on the ceramic object to which the procedure is applied. The fairly laborious technique of dowelling has often been applied to porcelain objects, as seen in the eighteenthcentury Meissen serving dish. (Figure 37) Dowelling was a common practice during the Victorian period, and its fundamental basis is still used by conservators in the twenty-first century. ${ }^{59}$ The procedure falls under the category of material substitution and is typically reserved for the reattachment of pieces that are relatively cylindrical in shape. Dowelling is substantially less visually-intrusive than riveting and provides more structural stability internally throughout the object. The technique involves drilling holes into the constituent pieces of a broken ware, inserting an adhesive into both holes, and affixing a dowel made from metal or wood into both holes, adjoining the pieces. Essentially, the inner-ceramic material is being replaced with either metal or wood in order to further stabilize the clay object.

${ }^{59}$ Nigel Williams, “Porcelain Repair and Restoration,” (British Museum, 2002): 18. 
In many cases, the material of the initial dowel dictates whether the restoration is considered stable by contemporary standards. Ultimately, restorations with dowels made from wood should be immediately revisited and retreated. The material nature of wood is one that undoubtedly decays and decomposes over time. Because of this, the overall safety of the piece is jeopardized due to the weakened section. However, in the case of the Meissen dish the dowel is made from iron. Logically, one would think that because the dowel is made from metal, that the section of this ceramic object is considered secured and stabilized indefinitely. However, there are indeed both pros and cons to this attribute. First, it is important to reiterate that a metal dowel is superior to a wooden dowel.

Although both materials can deteriorate and change compositionally over time, a wooden dowel is ultimately less able to withstand and maintain its strength over an extended period time and is more susceptible to the effects of atmospheric conditions. These include environmental elements such as moisture, humidity as well as aridity, temperature fluctuations, and even pests, all of which would quickly affect or jeopardize the stability of the Meissen dish. ${ }^{60}$

Since the "foot" of the dish has been implanted with a metal dowel, a few concerns should be addressed. Although metal is relatively stable, it does bear the possibility of swelling or expanding in adverse conditions. In the event of metal expansion of an implanted dowel, the effects can range from cracking of the surrounding surfaces to a complete break-up of the porcelain object. When it comes to metal dowels, a material hierarchy does exist in terms of the level of thermal

${ }^{60}$ Helen Alten, Collection Care and Management workshop series, Grave Creek Mound Archaeological Complex, Moundsville, WV. March 12, 2011. 
expansion exhibited by various metals. The Meissen dish contains a dowel made from iron, which is actually the optimal choice. In terms of thermal expansion and contraction, iron material is the metal least liable to swell in altered conditions due to the fact that the intramolecular forces of iron are considerably stronger than that of brass, nickel, and copper. ${ }^{61}$ These forces essentially hold the atoms together more tightly, making it increasingly difficult for the atoms to become activated when a temperature fluctuation is introduced.

Unfortunately, the downfall of having the dowel made of iron is that it is likely to corrode, or rust. To its detriment, the process of iron corrosion is quite simple. As long as there is oxygen in the atmosphere of the iron dowel, paired with slight moisture or humidity, it will undoubtedly rust. As a result, the surrounding areas in contact with the dowel may become stained by inorganic substrates such as hydrated iron (III) oxide and iron (III) oxide-hydroxide, the primary compounds produced by corrosion. The exposed iron dowel on the Meissen dish does indeed exhibit corrosion and the beginning stages of staining. Unlike the processes involved in the cleaning of organic-based stains, usually accumulated with day-today use over time, the removal of inorganic stains is slightly more severe. With organic-based stains on porcelain, it is possible to remove the stain with a mild stain-removing solvent or cleaning agent, such as hydrogen peroxide or even a mild detergent, such as Ariel. With an inorganic-based stain, the utilization of a more aggressive reagent, such as phosphoric acid, may be necessary in order to remove the stain. Because phosphoric acid is an overtly strong chemical to introduce to

61 P.E. Shaw, The Magnetic Expansion of the Less Magnetic Metals, Proceedings of the Royal Society of London Vol. 72. 1903-1904, 370-378 (370.) 
porcelain, often causing etching or roughing of the clay's surface, the procedure is somewhat risky and would require the conservator to ensure that absolutely no chemical residue of the acid be left on the object. ${ }^{62}$

Considering the overall condition of the Meissen dish and the context in which it is displayed, it seems appropriate that the metal dowel be removed and the piece be stabilized with an alternative material or method. The dish has been substantially damaged; the justification or purpose of displaying the work publicly would be primarily to exhibit the incised lattice-design and brushwork on the side, or rim, of the dish and also to reveal the detail of the molded fish form on the foot. The piece would not be representative of the cohesive, unscathed condition of other Meissen wares, but rather would be a study of the detail and exquisite linear quality indicative of the Meissen porcelain aesthetic. In other words, the dowel does not need to be removed and replaced in order to restore structural stability or even aesthetic quality. Instead, the primary concern lies within the instability of the dowel itself, threatening the safety as well as the overall lifespan of the sculpted form by which it is surrounded. This is where immediate focus and attention needs to be directed in order to save the key component of the ware.

Possible alternative methods that would be suitable in the reconnection of the sculpted foot to the dish involve the utilization of a strong adhesive appropriate for porcelaneous claybodies and a filling-material that compensates for the void of the missing piece(s). Because the level of loss is especially significant in the molded foot section of the dish, it would be inappropriate to fill the entire void with the

${ }^{62}$ Nigel Williams, "Porcelain Repair and Restoration,” (British Museum, 2002): 47. 
intent of completely disguising the flaw. In this case, the use of a filling-material such as a kneadable epoxy-putty would act in accordance with the necessity of restoring the overall form of the missing piece without falsifying any information concerning the piece's condition. As for the adhesive used in this procedure, a nonyellowing, clear epoxy-resin such as Araldite 2020 or Fynebond would be sufficient. Both are known to supply a very tight bond, are relatively inexpensive, and are better-suited to the needs of porcelain restoration versus terracotta or stoneware restorations.

Luckily for the Meissen dish the dowel has been exposed, making its presence known. Because of this, the handler of the object would be instantly aware of the potential structural weakness, and could then provide the appropriate management and care the piece requires. However, in many cases the dowel is concealed within handles, spouts, and knobs. These components are typically the first places where a utilitarian ceramic object is picked up and are extremely susceptible to mishandling which can lead to the total loss of an entire artifact. The best detection method would be to have the object X-rayed, exposing both the angle of the dowel as well as the amount of space the dowel encompasses.

In terms of total object replacement in utilitarian ceramics, the most commonly seen repair is that of the handle, spout, or lid. [Figure 36, 38] But there are several variations of this type of restoration, some requiring extremely laborious and meticulous procedures in order to recover any amount of the object's initial context. [Figures 39-40] What is fascinating about these restorations is the level of artistry and attention to detail in which they were made. Both the Meissen 
teacup [Figure 38] and the Meissen figurine piece [Figures 39-40] demonstrate this artistry. The handle of the teacup is thought to have been dated to the mid-1800s and is made from forged bronze presumably by a blacksmith. The metal handle conveys a refined sensibility due to its slender profile and elegant curvilinear quality. The addition of this element responds to the delicacy of the porcelain and complements the teacup's original features.

This type of artful restoration creates an interesting forum for conservators in regard to how, or if, the object should be treated. The addition of the metal handle does abstract the original context of the teacup, but is it falsifying pertinent information? Does it jeopardize the stability or challenge the artistic merit of Meissen porcelain? Because of the two holes exposed on the interior of the teacup, it can be presumed that it is no longer employed for utilitarian purposes, but would be kept rather as a display piece. As long as the object is kept in a stabilized environment and its condition is monitored regularly, the metal handle imposes no apparent threat to the teacup. In fact, the bronze handle serves as an ideal example of how an antiquated, yet quite successful restoration is just as important to preserve as the artifact on which it is placed. Restorations such as this also reveal information about material technology as well as the unification of craft trades. One must keep in mind that technology in the mid-1800s did not permit restorers to consider the future of the pieces. Their primary goal was to fix or repair, not necessarily to preserve and conserve. In this case the application of the bronze handle paired with the porcelain cup encourages new, or original, interpretation of both materials independently. Although the resulting product may not be analogous 
to the original teacup, the justification behind leaving the bronze handle in place takes precedence over the reason to remove it.

Unlike the teacup, the drastic measures taken in the replacement of the lower portion of the Meissen figurine raises concern. The entire bottom portion of the barrel has been reconstructed from wood. The only reference available for the restorer to access is the small upper portion of the lid. After researching the piece and its possible identity, it appears there are few, if any, other similar porcelain works from Meissen. This leads one to believe that either the initial restorer or owner possessed knowledge of the figurine's original model or that the reconstructed portion had been designed solely from the available information on the remaining upper piece. This leaves quite a bit of room for individual interpretation on the restorer's part. Although a successful restoration, when properly used, is an invaluable aid to conservation, it becomes reprehensible when its sole purpose is deception. ${ }^{63}$

However, there is some validity to the restorer's design. It can be presumed that the barrel upon which the figure sits does indeed reference a wine barrel, due to the bundle of grapes the figure grasps in his left hand. The restorer crafts the wooden replica with great detail [Figure 41] but ultimately fails to properly complement its counterpart. The paint job on the wood does not mimic the line quality on the porcelain; it appears clumsy and does not attempt to capture the realistic wood-grained pattern as the top piece does. Furthermore, the hue of the wooden restoration does not synchronize with that of the porcelain, leaving a strong

63 George Savage, Introduction to "China Mending and Restoration," by Claudia Sydney Marie Parsons, London: Faber \& Faber, 1963. Pg 7. 
visual and material-based disconnect between the two objects. Essentially, the restorer assumed too much in this case. With the restored portion making up over fifty-percent of the overall object, the figurine loses both its grandiose character and identity as a Meissen work.

The proper remedy for this situation could proceed in many directions. Due to the general lack of information surrounding the Meissen figurine, and works similar, it would be considered presumptuous even for the present-day conservator to reconstruct the bottom portion with the intention of creating an equal counterpart to the porcelain. However, if that bottom piece were to be created in a manner that adheres to the notion of not falsifying its own identity as foreign material, the restoration could be deemed appropriate. The wooden base would then need to be substituted with a material that is neutral and completely unbiased. Perhaps a prototype of the bottom half of the barrel could be sculpted and serve as the primary form from which multiple molds are cast. The conservator could then experiment with different materials (i.e. plasters, resins, clay) until the optimal result is achieved. The proper protocol for this object is slightly ambiguous due to the diversity of possible options or routes the conservator may employ.

One could argue that in both cases of the Meissen teacup and figurine the restorations are considered forms of deception. However, in the case of the teacup the intention of applying the bronze handle was not to portray the handle as something it is not. The surface of the bronze had not been treated to appear smooth and shiny like that of porcelain and it had not been painted to try to fool the viewer of its material composition and visual characteristics. Even from first glance 
the viewer is informed that there has been a material substitution. But in the case of the figurine, the viewer becomes slightly confused as to the identity of the material composition of both segments as well as to their purposes of functioning as a cohesive unit. The wooden replacement is a form of deception and imposes a threat upon the integrity of the overall artifact.

In any case, the primary focus for both objects should be to stabilize and protect, followed by appropriate representation of the figurine and its display. There is small divergence as to whether or not these ceramic objects should be restored, but the question may be to what extent? It seems only suitable that both material structure and art historical attributes be assessed by both conservator and proprietor when making these decisions. 


\section{Case Study 3: Fürstenzug Mural}

The art of ceramic mural installation comes from a long lineage of practitioners wishing to communicate and portray belief systems, socio-political structures, significant events from their lifetime, and historical events both real and imagined. The oldest known example dates back to the cone mosaics made from clay and mud plaster of ancient Mesopotamia from the Late Uruk period. ${ }^{64}$ Technological advancements throughout the centuries have allowed ceramic material to be progressively transformed to accommodate the demands of ambitious sculptors, alchemists, and craftsmen. This advancement resulted in the elevation of the material's status, at one point even earning the name "white gold," during Europe's porcelain wars in the seventeenth century. ${ }^{65}$ The world's largest porcelain ceramic mural, the Fürstenzug mural [Figures 42-43] in Dresden, Germany, demonstrates the complexity of the ceramic mural. Ceramic murals are erected but also dismantled regularly due to the fragility of certain types of fired clay and the compositional impermanence of the grout or adhesive used to secure constituent pieces. But when the mural has become a civic work of art and form of social identification, in terms of both iconographic content and technological advances, it is imperative that special considerations and repercussions be analyzed when issues of restoration and conservation protocol arise.

How does the porcelain composition of the Fürstenzug mural compare to contemporary clay recipes designated for outdoor murals and what are the

${ }^{64}$ Cone mosaic [Excavated at the "Columned Hall," Uruk, Mesopotamia], Heilbrunn Timeline of Art History, The Metropolitan Museum of Art 48 (1995): 2.

65 Janet Gleeson, The Arcanum: The Extraordinary True Story (New York: Warner Books, 1998), 13. 
technical and aesthetic similarities or differences? How is this material holding up in present day and has this antiquated recipe proven successful over time in being exposed to the elements of Eastern Germany? Do certain benefits and disadvantages of the materials reroute restoration procedures? Technological advances in ceramic media and restoration materials, paired with the contextual importance of the mural, help guide conservation protocol. This portion of the paper will explore the answers to these questions and assess the importance and repercussions of conserving the Fürstenzug mural.

The Fürstenzug mural is an interesting case due to its multifaceted nature. It serves as a source of civic remembrance and pride, a representation of the prestigious artistic and technological innovations of Saxony, and also as a major tourist attraction of contemporary Dresden- it is a core element of the community. It can be seen as an example of what twentieth-century architectural critic Jane Jacobs wrote about on the issue of art's role within the community:

We need art, in the arrangements of cities as well as in the other realms of life, to help explain life to us, to show us meanings, to illuminate the relationship between the life that each of us embodies and the life outside us. We need art most, perhaps, to reassure us of our own humanity. ${ }^{66}$

The commissioning of the Fürstenzug mural installation in the early twentieth century by the Saxon government was an act to reaffirm Saxony's contributions

66 Jane Jacobs, The Death and Life of Great American Cities (New York: Random House 1961), 372. 
toward the forward progression of society, art, and technology. ${ }^{67}$ Its existence today serves as a reminder of that forward progression as well as a reflection of the accomplishments made by German government and society.

The Fürstenzug mural was installed on the east wing of the Dresden Palace in 1907. It consists of 25,000 singular tiles (roughly 6" by 6") manufactured by the Meissen Porcelain factory, it extends approximately 335 feet long and is 30 feet tall. 68 The mural was painted in "grand feu" colors. [Figure 44] In this process a colored slip is used to paint the imagery followed by the application of a transparent glaze and finished by a high temperature firing at a range of 2000 to 2600 degrees Fahrenheit. In turn the glass surface seals and protects the interior pigment of the slip. The mural portrays the Procession of Princes- a group of thirty-five historical dukes, electors and kings and fifty-eight contemporary painters, sculptors, architects. The ceramic mural was the second rendition of the Procession of Princes; the first interpretation was a sgraffito painting completed by Wilhelm Walther in 1872. The original painting consisted of only the historical figures (dukes, kings, and electors.) The painted mural lasted for fewer than five years

${ }^{67}$ In the mid-nineteenth up to the early-twentieth century in Germany, there was a strong anti-urbanist movement accompanied by a tense, unstable group of civilian followers bearing the potential for a revolt or revolution against the government. During this time, there were major efforts being made by Saxon city planners, architects, and local governments to improve the quality of city life and to encourage and restore German civic pride. The mural installation was an effort to display this national individualism and to restore the positive attributes made by Germany to its native communities as well as the rest of Europe.

68 "A View on Cities," http://www.aviewoncities.com/dresden/processionofprinces.html, accessed October 21, 2010. 
while its chalk rendering lasted until construction of the Meissen tile project began in 1904. ${ }^{69}$ The Meissen mural is a more all-encompassing interpretation of the Procession of Princes due to its inclusion of contemporary artists and architects dressed in modern twentieth century attire. [Figure 45] The intent of this arrangement was to inspire the Saxon community with a message relaying that greatness and achievement were attainable and relative to both historical and contemporary Germany.

This message was significant for Saxony considering the recent unification of the German Empire in the late nineteenth century. In addition, it was the impermanence of the sgraffito painting that inspired the use of a more resilient, stable material, porcelain. The creation of this porcelain remains a fundamental part of German history and is still revered today. The prestige of Meissen porcelain is based equally on aesthetic quality and scientific invention. It is just as much regarded an art as it is a science, justifying it as an architectural medium.

This hard-paste porcelain had been modified a few times since its initial discovery to resolve cracking and bloating issues, and the recipe in use during the time of the Fürstenzug mural's construction is outlined in Figure 46. When compared to the chemical composition of traditional "china clay" or Chinese porcelain [Figure 47], notable similarities and differences are evident. Generally, the primary components in porcelain are silica, feldspar, and alumina- a glass former, a flux, and a stabilizer, respectively. Meissen's silica is lower in percent

69 "Travel Germany in English, the Fürstenzug Mural," http://www.travelgermanyinenglish.com/dresdenfurstenzug.html, accessed November 2, 2010. 
composition than that of Chinese porcelain with higher percentages of flux in the form of $\mathrm{K}_{2} \mathrm{O}$ and $\mathrm{Na}_{2} \mathrm{O}$ and substantially higher percentage of Alumina $\left(\mathrm{Al}_{2} \mathrm{O}_{3}\right)$. This suggests the white clay mined from the Schneeberg and Colditz mines was potentially a structurally harder composition when fired. Meissen's composition proved to be nonreactive to the glaze. This resulted in an extremely smooth and translucent surface, uninterrupted by bubbles or crazing, which is difficult to create even today. ${ }^{70}$ [Figures 48-49] Because of this quality, glaze could be very thinly applied yet remain incredibly smooth and clear. This explains the extreme clarity of the clear-glazed sgraffito decoration on the Fürstenzug mural. However, this thinlyapplied glaze can potentially lead to the mural's deterioration, as later discussed in this chapter.

There is a specificity of material choice when it comes to exterior or outdoor ceramic art in terms of longevity and resilience. That is to say, early 1900's porcelain was not the preferred material used in outdoor tile installations due to its high cost and primary role as a pottery-art material. Furthermore, if porcelain tiles were to be used anywhere, they would be installed as floor tiling for their durability and strength. In general, outdoor tile work was scarce in northern and eastern Europe, including England, due to inclement weather, surface crazing (or cracking)

\footnotetext{
${ }^{70}$ A. D'Albis, "The History of Innovation in European Porcelain Manufacture and the Evolution of Style: Are They Related?" Technology and Style. 2 (1986): 399. Figure 5 shows how modern porcelains fall short of achieving an equivalent smoothness in glaze. In modern porcelain bodies the glaze must be applied very thick to mask the bubbles which the firing process produces between the clay body and enamel, resulting in the loss of translucency.
} 
on the tiles, and failed attempts with various adhesives. ${ }^{71}$ Large-scale outdoor tile work that was constructed in the early twentieth century was typically made from earthenware or terracotta, or some low-cost and low-risk clay body. These clay bodies were marginally sufficient and when they cracked they were easy and inexpensive to replace. Although the Meissen porcelain tiles proved to be a more expensive and substantially more ambitious project, they were also a great deal more stable.

Proof of this stability can be seen in the current state of the Fürstenzug mural. The compressive strength of the tile arrangement along with the durability of the adhesive allowed the mural not only to survive the surrounding destruction of Dresden during World War II but also to be in respectable shape today. Other factors aiding in this longevity are the compositional strength of the porcelain and the manner in which the tiles were produced. Most likely, the tiles were made by some type of mechanical press. [Figure 50] It is presumed that the aid of industrial machinery and presses were used in the tiles' construction for two reasons. The first reason is that handmade tiles bear inconsistencies in clay particle dispersion which can result in dimensional (size) inaccuracies, due to uneven shrinking of the clay body. ${ }^{72}$ The second reason is that ceramic tile companies throughout England and

${ }^{71}$ Julian Barnard, Victorian Ceramic Tiles (New York: Graphic Society Ltd. 1972), 134.

72 G.L. Efremov, "Effect of the Shape and Distribution of Clay Particles On Shrinkage of Products," Glass and Ceramics 14 (1957): 1.

"The shrinkage of a ceramic product differs in different directions in accordance with the orientation of the particles in the body. For example, porcelain wares made by extrusion through a die shrink to different extents in longitudinal and transverse directions: the transverse shrinkage exceeds the longitudinal by 7-8\%. The main 
the Netherlands had been employing these machines and presses since the mid1800 s and it is unlikely that the Meissen factory would not have access to similar type of machinery. ${ }^{73}$ The uniformity, evenness, and tightness of the tiles' arrangement suggest that some sort of press was utilized.

Although the porcelain has held up relatively well over a century's time, there is evidence of material degradation and discoloring due to both exposure from the elements, architectural shifting, and a previous restoration effort. After examining the mural's condition, there seem to be four forms of material degradation and/or material inconsistency: slip pigment leaching, discoloration from tile replacement, cracking and separating, and discoloration from previous restoration.

Possible slip pigment leaching, as seen in Figure 51, may be a result of moisture exposure. This could have resulted from moisture leaching in from the unglazed obverse of the tile or from direct cracking. As mentioned earlier, the thin layer of glaze application could perhaps not be sealing the interior tiles as well as a thicker layer of glaze could. These pigment "stains" suggest that the interior slip layer may not be fully vitrified, causing the pigment to streak down the surface of the mural. This could be a mishap on the factory's account, but it cannot be determined without more in-depth analysis involving the potential removal of the tile. Due to the level of secrecy the Meissen porcelain factory maintained in regard to its clay and glaze recipes, it is difficult to assemble a precise slip recipe for this factor causing cracking and deformation of porcelain ware is orientation of lamellar and elongated mineral particles in the porcelain body."

${ }^{73}$ Barnard, 74. 
mural. However, it is likely the slip recipe contained both lead oxide and manganese dioxide for practical reasons. Manganese dioxide was, and is, a popular compound used in ceramic slips and glazes in order to achieve a strong black color. Lead oxide was a popular fluxing agent used in abundance throughout Europe, as well as in the rest of the world, due to its availability in accessible mines. Both compounds are considered highly toxic and unhealthy to handle or breathe without any protection, so disturbing such compounds must be addressed with precaution. The leaching could also be a result of an interaction the slip had with the glaze during the firing process. In which case, the imperfection is sealed within the tile and should remain as part of the mural. In the case of the slip pigment leaching, what is the treatability of the situation?

This question relates to the issue of tile discoloration as some tile has been replaced in previous restoration efforts. Depending on the severity of the defect, tile replacement can have both positive and negative repercussions, as seen in Figures 52 and 53. One positive aspect of tile replacement is that a newer, more technologically advanced material can replace the deteriorated one. Another aspect is that the adhesive used to secure the tile will also be of a higher quality, increasing the longevity of the tile's placement. However, in the case of the Fürstenzug mural where the material's composition is vital to its identity, it would seem inaccurate or unjust to continually replace defected tiles with those from other "technologically advanced" recipes. At some juncture in time, a so-called "tipping point" would be reached at which time the identity of the mural would be jeopardized. In addition, tile replacement results in color differences due to variations in mined materials. 
Mines that harbored specific materials may be mined out and mines that contain similar materials can differ in compositional makeup, altering the fired results. Also, slip and glaze recipes are specific, containing exact percentages of colorants and fluxes. To be able to match the color or hue of the tile could prove difficult. So if a restoration or tile replacement were to be performed in accordance with original materials, the results may not render true to the original palette of the mural. Similarly, a tile replacement not based on the original composition but based on advanced durability may still result in a color variation, as seen in Figure 53. In brief, tile replacement should be used sparingly and only when the tile is a total loss or is completely absent from the mural, with the goal of maintaining as much original aesthetic quality and content as possible.

The cracking and separating seen [Figures 54-55] is an interesting case due to the ambiguity of the cause of the cracking. Porcelain of this nature is impervious to weather: it has such a vitreous nature that its absorption of water ranges from zero to one percent. ${ }^{74}$ However, there are areas of severe cracking seen in the mural. Although the porcelain is highly unreceptive to water absorption, it is not glass, meaning that the cracking and separating seen in the porcelain is very likely from some kind of exposure to water. This exposure could be through a crack that had initiated on the tile's surface or through a weakening adhesive, allowing the water to penetrate the obverse of the unglazed tile. It has also been suggested that the cracking could be a result of shifting architecture. ${ }^{75}$ This, too, is a likely

\footnotetext{
${ }^{74}$ Jeff Greenham, Phone Interview by author, Morgantown, WV, 11/06/2010.

${ }^{75}$ Jeff Greenham, Interview, 11/06/2010.
} 
hypothesis due to the age and material of the building to which the mural is attached. The architecture upon which the mural is mounted dates to the sixteenth century. It is made from sandstone, a relatively soft stone in terms of building materials. Some of the cracking extends consistently through multiple rows of tiles, suggesting there is a stress occurring within the building façade or in the adhesive used to secure the tiles. In either case, a structural engineer must be consulted to assess the structural integrity of the building. ${ }^{76}$ Interestingly, a crack in the mural due to the inferiority of the architecture upon which it is secured only validates the strength of the porcelain.

Should water be the culprit responsible for the cracking and separating, what is actually happening is the water is freezing and thawing and essentially expanding and contracting within the tile's surface. Freeze-thaw cycles occur when there is a way for water to seep below the surface of the tile into the substrate and then crack and break apart when it freezes and expands. ${ }^{77}$ This constant exposure over the period of a century explains the level of cracking seen in the mural. In this case the appropriate action of the conservator would then be to remove any pre-existing deteriorating adhesives, clean the area, and then apply the appropriate compound necessary to seal the area.

As previously stated, restoration efforts were made on the Fürstenzug mural in the late 1970s. When examining some of the preexisting cracks, there is a

${ }^{76}$ Michael Belman, Phone Interview by author, 11/11/2010.

77 C.M.F. Vieira, and S.N. Monteiro, "Evaluation of a plastic clay from the state of Rio de Janeiro as a component of porcelain tile body," Materia 12 (2007): 1. 
considerable amount of discoloration seen in both the areas surrounding the crack as well as in the darkening of slip pigment bordering the crack. [Figures 56-57] The lightened "patched" areas surrounding the cracks are most likely the results of the use of an adhesive with a limited lifespan. Upon close examination, the lightened areas are yellow in color, suggesting a level of degradation present in whatever adhesive was used. According to glass and ceramic conservator Norman Tennet on the subject of adhesive yellowing:

The optical properties and color of adhesives can have a decisive role in the appearance of restored ceramics. Perhaps most important is the yellowness, often determined as the Yellowness Index (ASTM 1970.) Degradation of adhesives can result in loss of strength, change in solubility and in the change of color, notably yellowing. ${ }^{78}$

Although the yellowing of the adhesive in the Fürstenzug mural is muted by the yellow color of the background, the discoloration is still evident and presents a case for an alternative adhesive to be applied. Another presumption about the adhesive used in the 1970's restoration is that it may be chemically reacting with exposed pigment which would explain the discoloration seen in Figure 56. In which case it would be necessary to find out if the treatment is reversible in order for the conservator to remove the substrate to prevent further discoloration. ${ }^{79}$

${ }^{78}$ Norman Tennet, The Conservation of Glass and Ceramics: Research, Practice, and Training (London: James \& James Ltd., 1999), 115.

${ }^{79}$ Barbara Appelbaum, "Criteria For Treatment: Reversibility," Journal of the American Institute for Conservation 26 (1987): 65.

"The 'Principle of Reversibility' is one of the factors which establish [conservators] unique intent to project our work into the distant future. Conservators have an obligation to assure to the best of their ability that the condition of an object remain unchanged long after treatment is completed. Knowledge of how conservation 
There is a great deal of further analysis within each of these assessments needed that would allow the conservator to proceed with the actual restoration process. But it is within these initial evaluations that help inform and direct appropriate restoration and conservation protocols. Object examination and recording are crucial to fully understanding the complexity of not only the composition of the materials, but also the process by which the object was made. The creation of a record about a work of art recognizes that conservation and restoration work is not an end in itself but part of a series of important stages of documentation of information being passed along for the whole of the object's life. ${ }^{80}$

In the case of the Fürstenzug mural, where the identity of the tile's composition is just as important to preserve as its structural stability, a great deal of consideration must be taken before and during its conservation. The mural serves as a source of civic and cultural pride that represents both historical Saxony as well as the Meissen porcelain factory. From the initial condition assessment it can be recognized that the mural is in a relatively stable state but does contain some degradation, including tile discoloration, pigment leaching, and cracking. Proper restorative processes would not only help the Fürstenzug mural maintain its iconographic and historical significance but would also extend the mural's life span, allowing its legacy to be passed along to future generations. In conclusion, the Fürstenzug mural case is a prime example of how thorough historical and material

materials age, how they interact with the object, and how the object responds to its environment is therefore necessary to fulfill this obligation."

${ }^{80}$ Chris Caples, Conservation Skills : Judgement, Method, and Decision Making (London and New York: Routledge, 2000), 70. 
research can help inform restoration procedures and ultimately lead to a successful conservation project. 


\section{Conclusion:}

The creation of the first European hard paste porcelain by Johann Bottger and Ehrenfried Walther von Tschirnhaus in the eighteenth century remains an important milestone in both German and ceramic art history. The discovery represented the assertion for superiority in technological and scientific developments and the determination to dominate trade markets, but most importantly it signified a desire for independence and originality. The artists' work produced at Meissen challenged the conventional preconceptions surrounding clay media and its place within society and art. The directed audience of upper-class society and their preferred tastes seemed to demand a new porcelain aesthetic, one that transcended the clay's former identity as solely Asian export ware. The new aesthetic embraced fine and decorative art, diverse materials, media, and processes. This new direction permanently modified the role of utilitarian ceramics in European society and also changed the context in which these objects were displayed. The composition of the European porcelain paired with the avant-garde techniques and the technologies involved in its production made it possible for the artists at Meissen to initiate and activate this transformation.

The resulting product of this metamorphosis consists of nearly three centuries of porcelain objects that have continued to inspire, influence, and captivate those fortunate enough to experience and comprehend their magnificence. Meissen porcelain is held in high regard by museum professionals, historians, conservators, and artists alike. Its legacy is one that demands proper representation as well as preservation. In order to accurately treat and protect these artifacts, the 
acknowledgement of Meissen porcelain and its individual characteristics and properties is necessary.

The purpose of this study is not to discredit Chinese or other variations of porcelain and the restorative processes applied to their framework. Rather, the analysis of Meissen porcelain and the precision, presentation, and preservation methods that embody its foundation initiates ideals of individuality when it comes to the assessment and treatment of porcelain media. There have been numerous extensive studies involving the history, manufacture, and technology of Asian porcelain wares and even more case studies performed on the restoration and conservation efforts applied to these objects. Through an examination of Meissen porcelain and its conservation with the same depth and rigor that has been applied to Chinese wares, a new subcategory of porcelain restoration can be progressively cultivated and established.

The specific case studies outlined in this paper- involving ceramic riveting, material substitution and object replacement, and the Fürstenzug mural- provide insight concerning how European porcelains may be treated. By combining the fundamental processes of porcelain restoration with new techniques discovered from the investigation of Meissen porcelain, the conservator is able to expand upon preexisting methodologies in conservation science. As a result, they are able to contribute to the overall body of knowledge concerning the methods of porcelain conservation. These new revelations involving the conservation of Meissen porcelain can be discovered through the in-depth study of site-specific materials, manufacturing techniques, and historical information indigenous to Germanic 
culture. By acknowledging and considering these factors, conservators can construct and provide more-informed and appropriate conservation protocol.

Through the bifurcation of this paper involving Meissen porcelain and both its history and conservation, a new type of knowledge base emerges. It is one that is approachable by historians and conservators alike, and can be identified as a middle-ground source between the two divisions. The overall objective of this analysis is to educate and inform individuals from both sectors, unveiling pertinent information from both fields and points of view. Because ultimately, the more important issue remains who, if anyone, owns the past? ${ }^{81}$ It is a complex question and the answer is often muddled by the politics and legalities linking museums, collections, and galleries. Nevertheless, it can be said that the owners of the past and its material relics are simply people, present and future generations of human society. In order to honor this guardianship, it is the duty of the conservator and historian to provide the most accurate information involving these relics in order to properly preserve their legacy. Through this preservation, the lifetime of material culture is extended. In the end, these relics provide future generations with the opportunity to experience and identify with the object, bestowing upon the viewer a sense of history, heritage, and identity.

${ }^{81}$ Karen J. Warren, Introduction to: The Ethics of Collecting Cultural Property: Whose Culture? Whose Property? By Phillis Mauch Messenger, University of New Mexico Press, 1989, 1. 


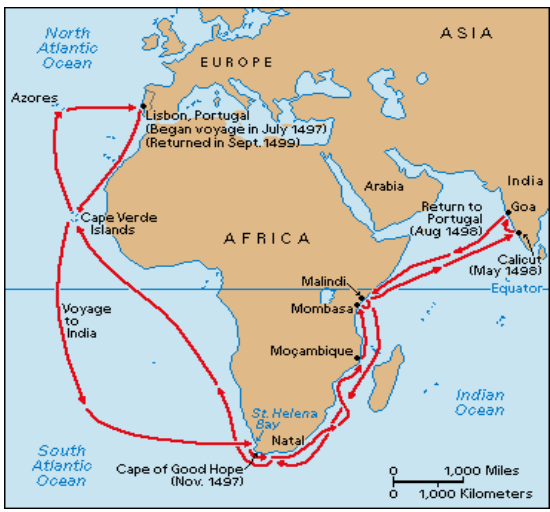

Figure 1.

Cape Route to India.

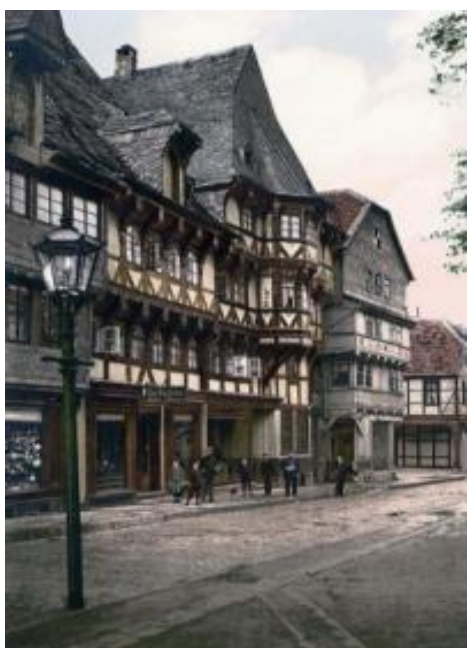

Figure 2. Goslar, Saxony. Example of $17^{\text {th }}$ century architecture in Germany.

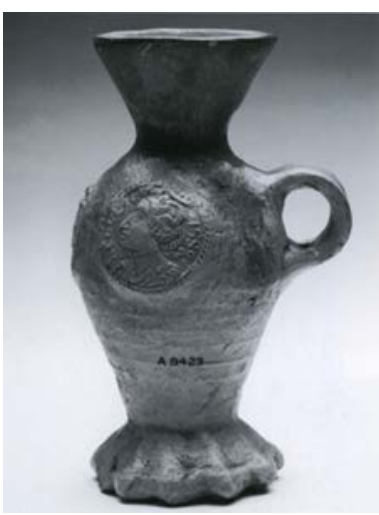

Figure 3.

Drinking Jug, German, 1586 CE. White stoneware with transparent ash-glaze.

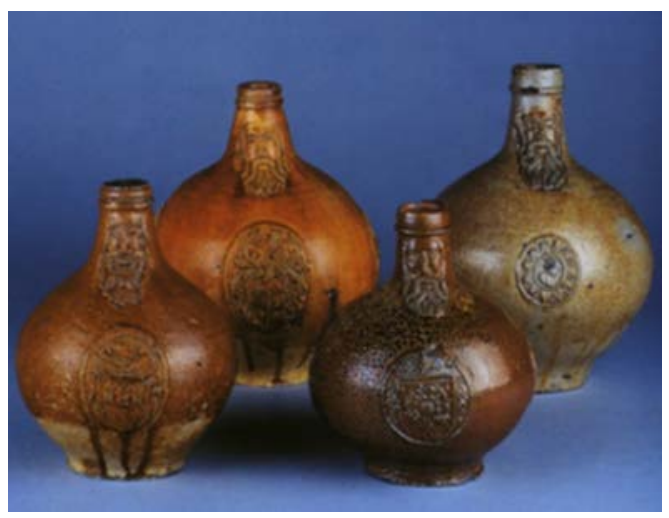

Figure 4.

Jugs, German, 1600-50 CE. Buff stoneware with iron wash and salt fired.

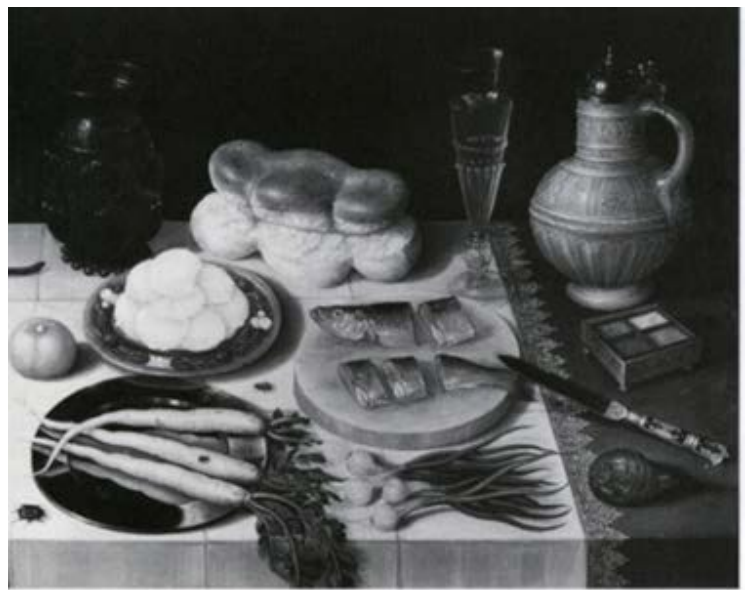

Figure 5.

Breakfast-piece, Nicolaes Gillis, 1622-32 CE, Dutch. 


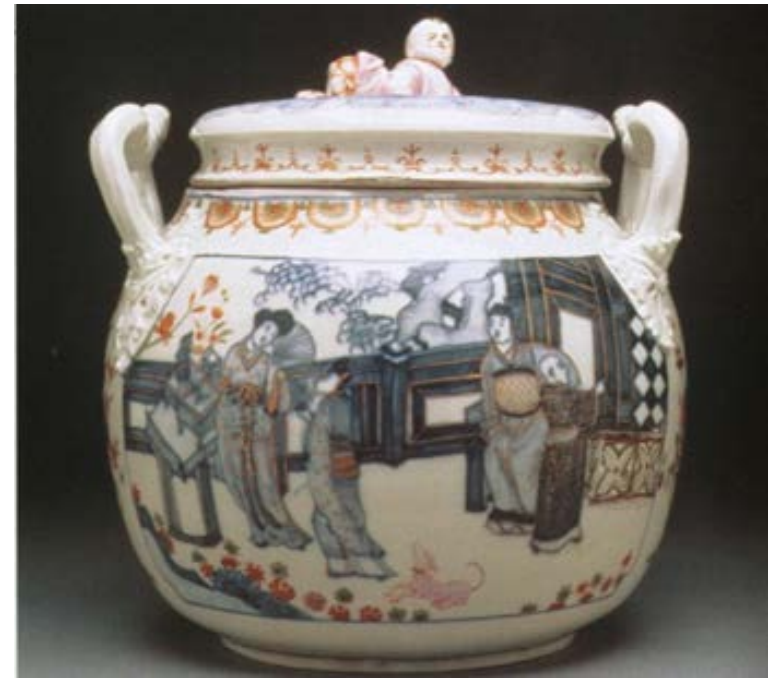

Figure 6.

Meissen tureen, $18^{\text {th }}$ century.

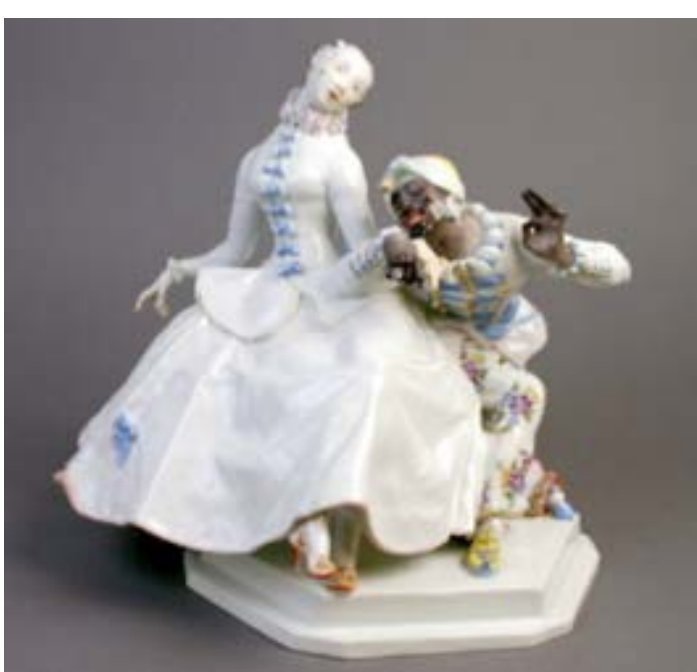

Figure 7.

Figurine. German. Meissen porcelain, ca $18^{\text {th }}$ century.

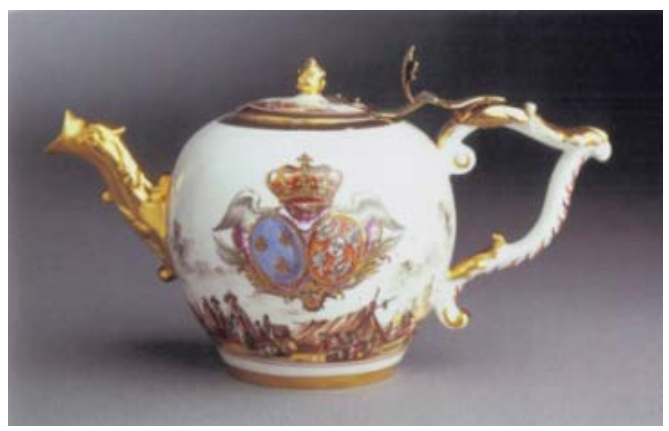

Figure 8.

Coat of Arms teapot. German.

Meissen porcelain. ca. $18^{\text {th }}$ century.

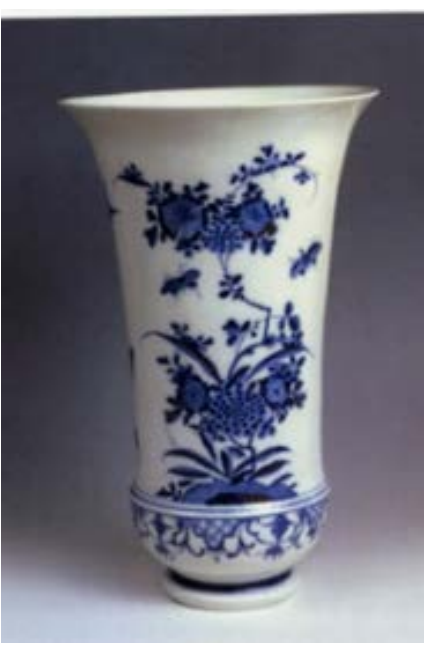

Figure 9.

Vase, German, Meissen Porcelain, ca. 1723-25 CE.

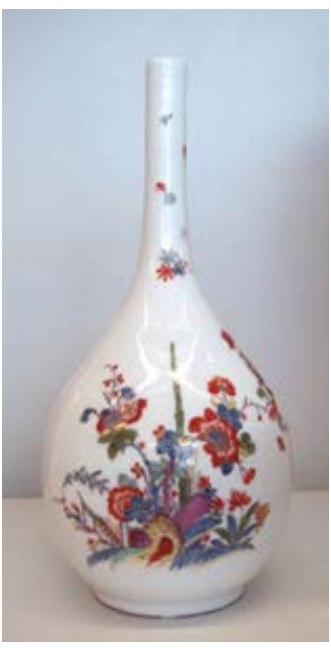

Figure 10.

Vase, German, Meissen Porcelain, ca. 1730 CE.

Kakiemon Style of Arita Japanese porcelain. 

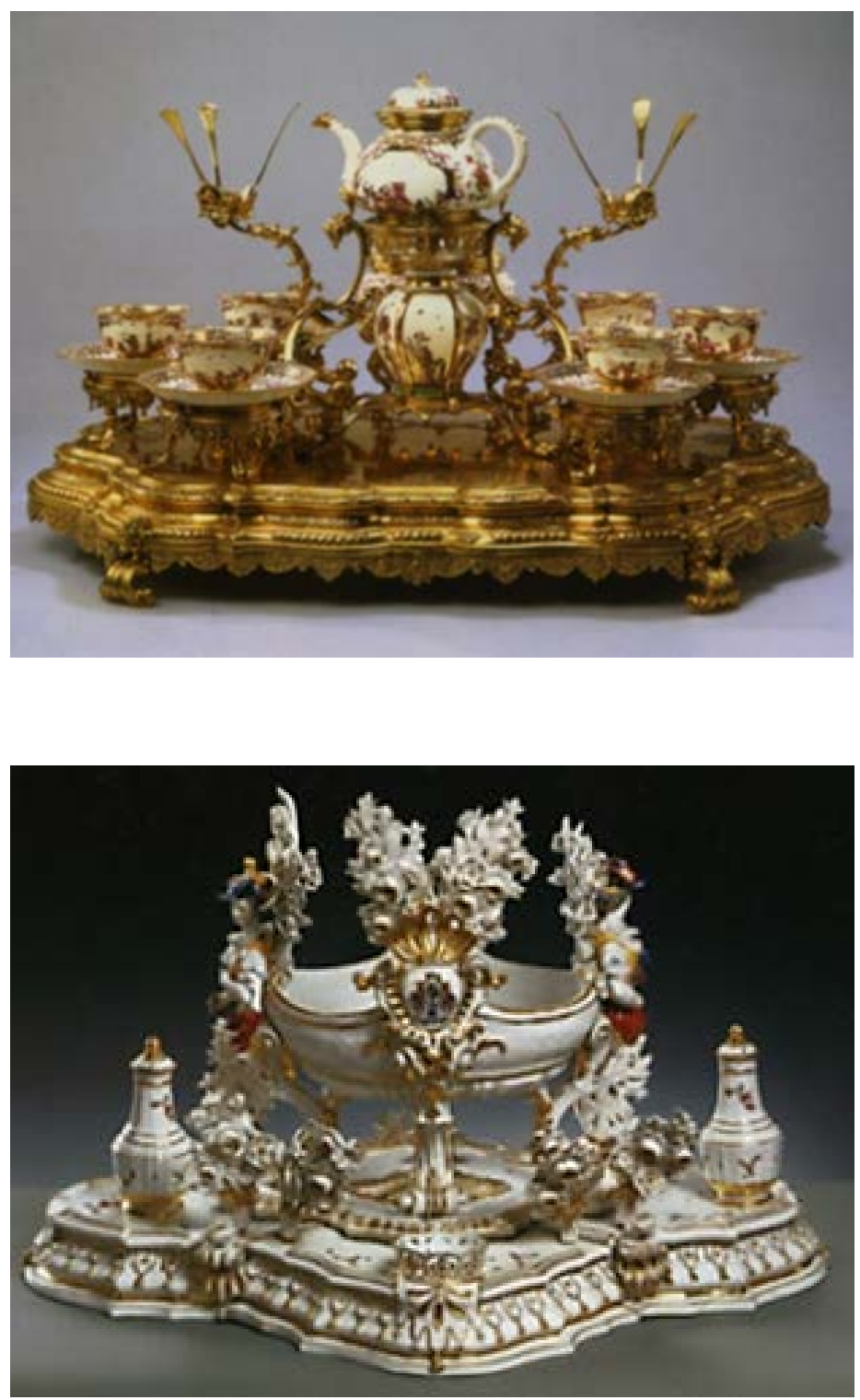

Figure 11.

Tea service, German, ca. 1723-24; stand, ca. 172833. Meissen porcelain; silver-gilt stand. Maker's mark of Johann Engelbrecht on the stand.

Figure 12.

Centerpiece from the table service for Count Burchardt Christoph von Munnich. Meissen porcelain, model by Johann Joachim Kaendler, German, 1735-36. 


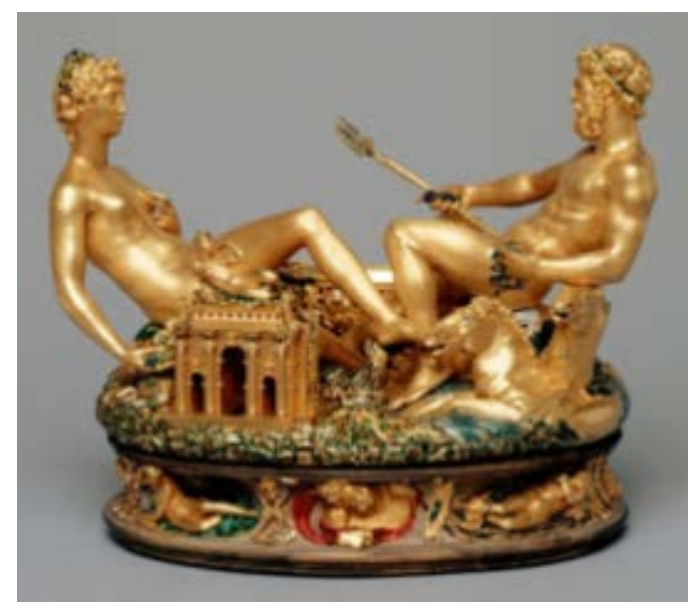

Figure 13.

Salt Cellar, or Saliera, Italian, Benvenuto Cellini, 1543 CE. Italy.

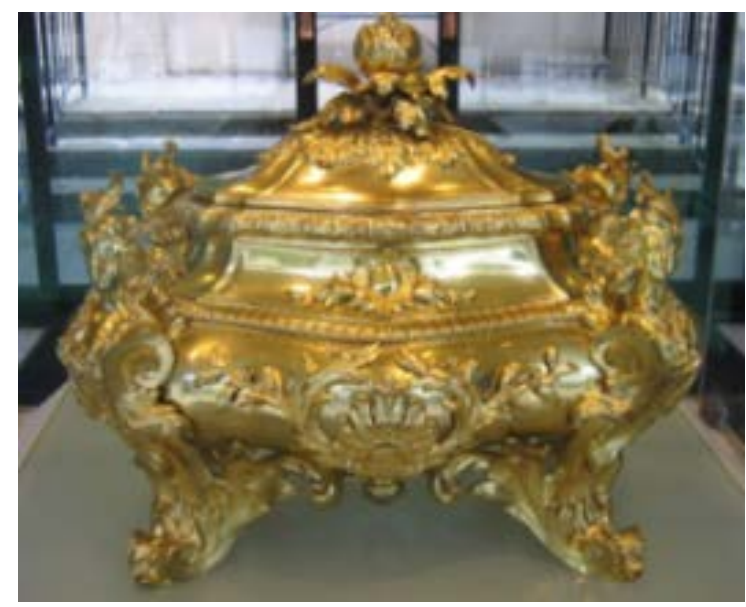

Figure 14.

Tureen, French, ormolu-brass, 1720-50 CE. Commissioned by Prince Marc de BeauvauCraon (1679-1754.

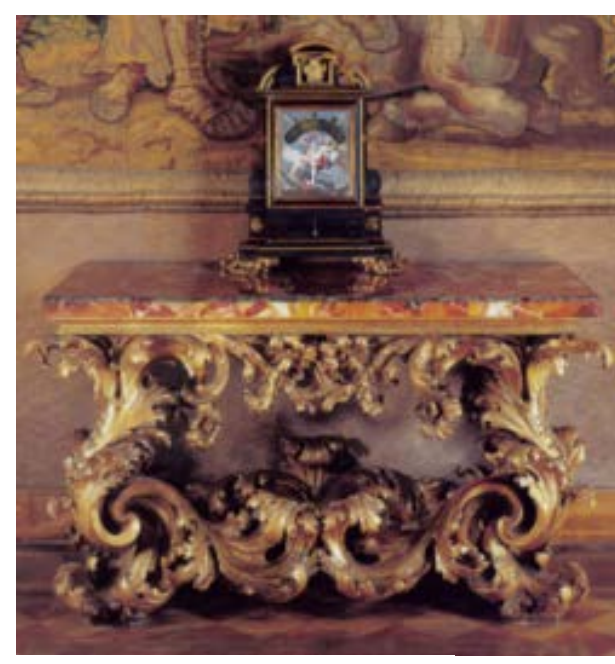

Figure 15:

Console Table, 1680s-90s. Italian. Gilt wood, marble top. Artist unknown.

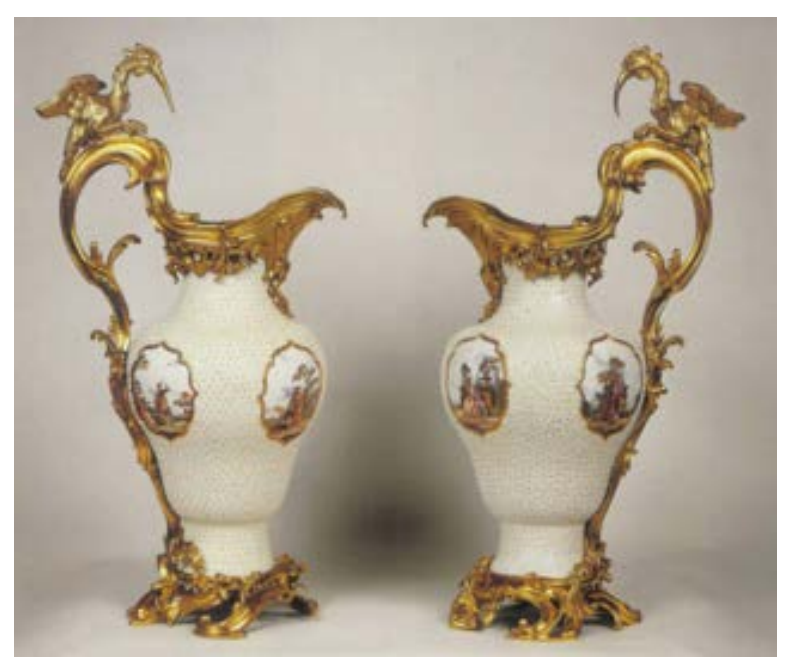

Figure 16:

Pair of vases mounted as ewers, ca. 1746 CE. German, Meissen porcelain. Example of ceramic "gilding" on surface.

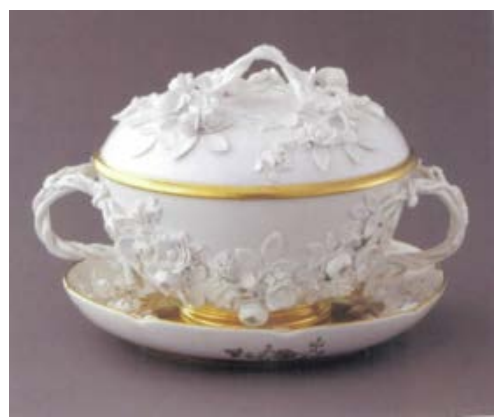

Figure 17:

Ecuelle, or covered broth bowl and stand, ca. 1740 CE. German, Meissen porcelain. Example of Vincennes flowers application. 
Comparison Images: [18-23]
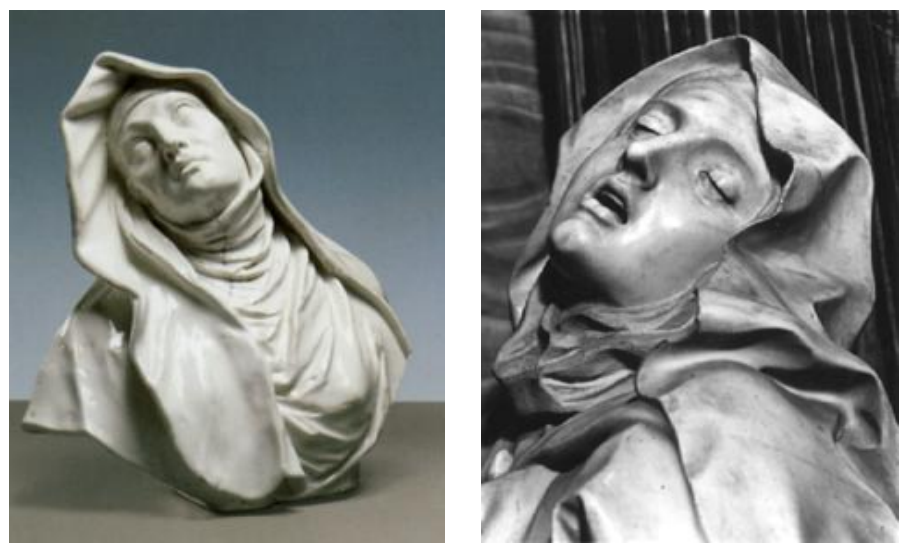

Figure 18. (left)

Bust of St. Teresa, 174344 CE. German, Meissen porcelain.

\section{Figure 19. (right)}

Close-up of Bernini's Saint Teresa in Ecstasy, 1652 CE. Italian.
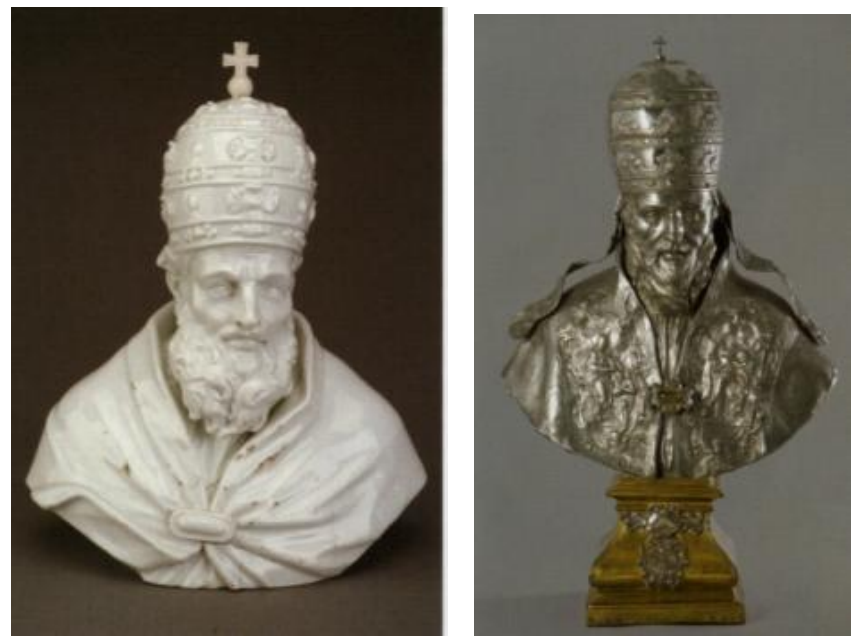

Figure 20. (left)

Bust of Pope, possibly Pius V, 1743-44 CE. German, Meissen porcelain.

Figure 21. (right)

Reliquary bust of Saint Urban, silver, 1706 CE. Giovanni Arrighi. Italian.
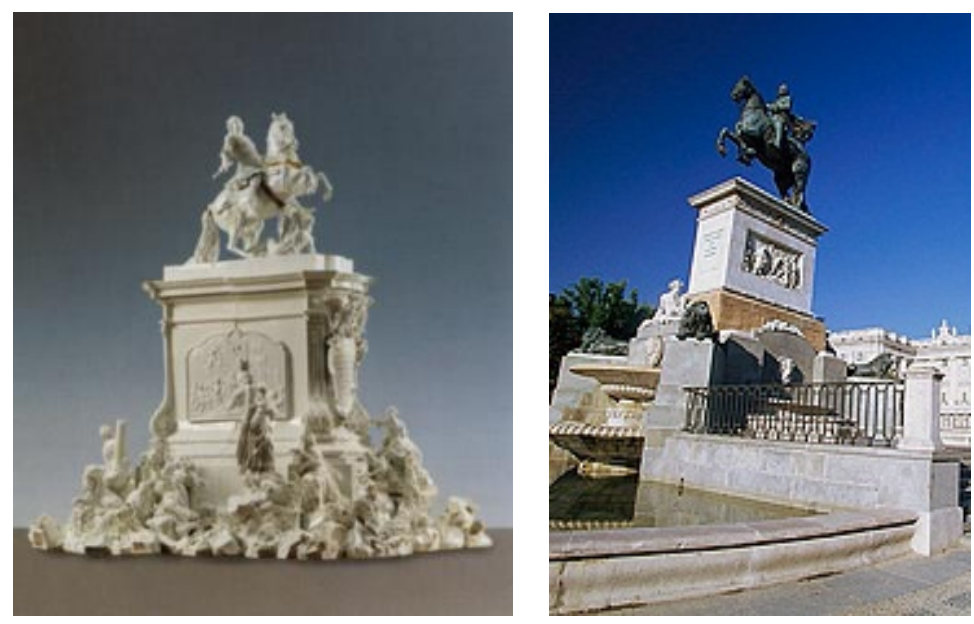

Figure 22. (left)

Equestrian monument model, German, Meissen porcelain, 1753 CE. Johann Joachim Kaendler.

Figure 23. (right) Equestrian Statue of Philip IV, bronze, 163440 CE. Pietro Tacca. Spain. 


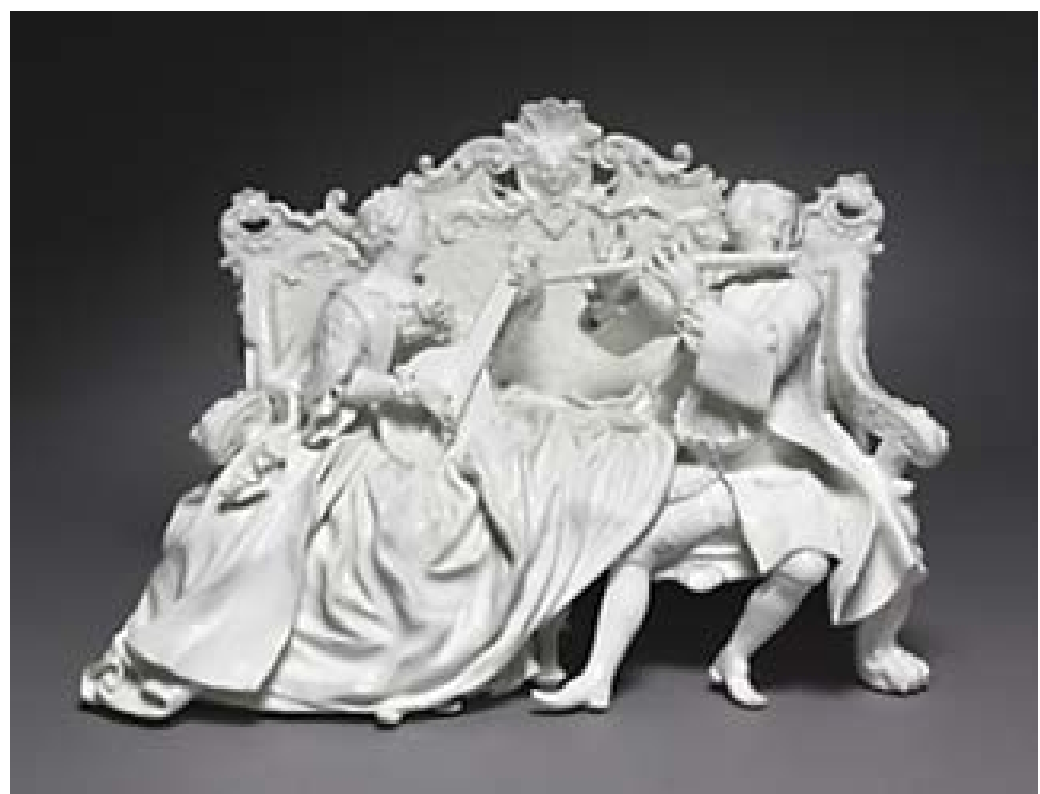

Figure 24.

Crinoline Group.

German. Johann

Joachim Kandler, ca 1737.
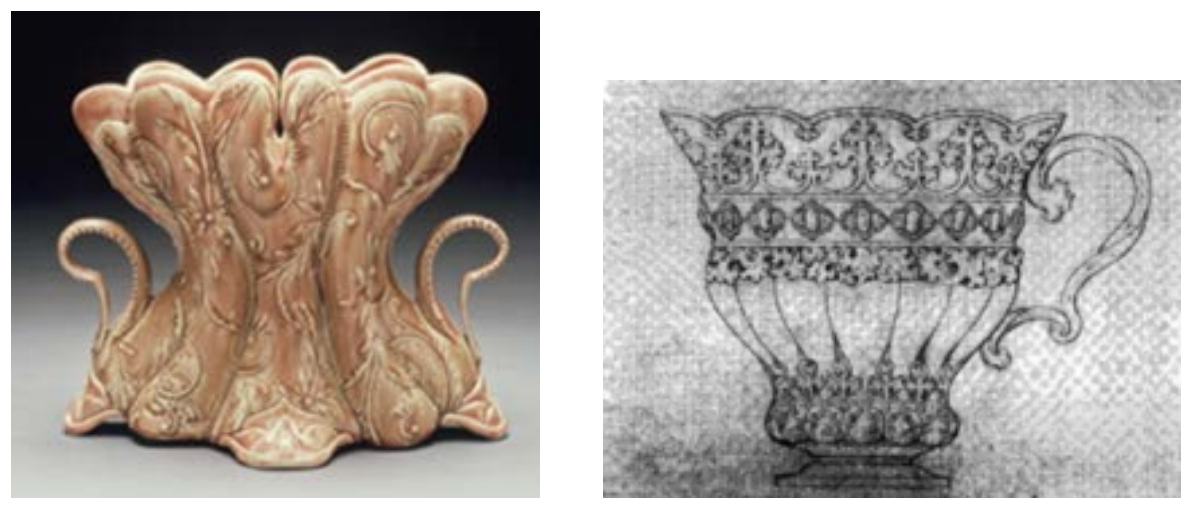

Figure 25.

Flower Vessel. Kristin Kieffer. 2008.
Figure 26.

Meissen Gothic prototype design. German. $18^{\text {th }}$ century. 


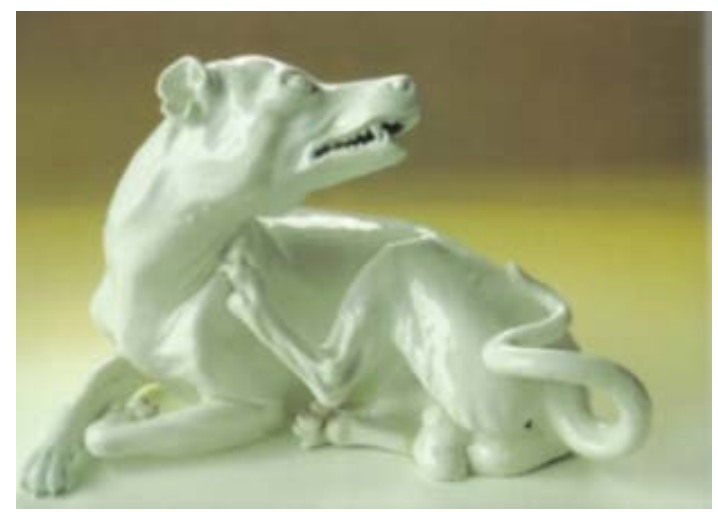

Figure 27.

Dog. Meissen

porcelain. Germany. ca

$18^{\text {th }}$ century.
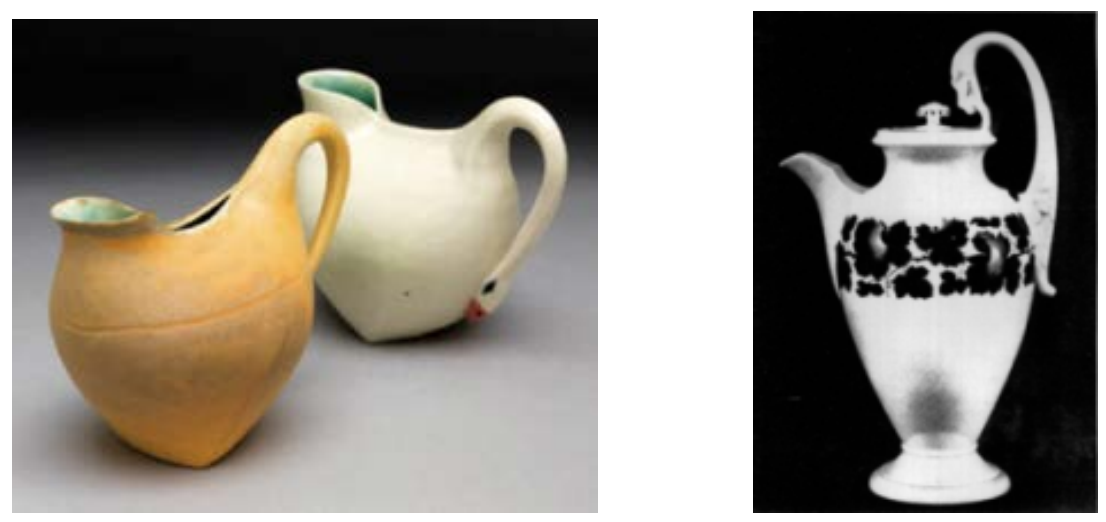

Figure 30.

Swan Handle Ewer. Meissen Porcelain. Germany. ca $18^{\text {th }}$ century.

Figure 29.

Swan Handle Cream Pitchers. Silvie Granatelli. Stoneware. 2008.

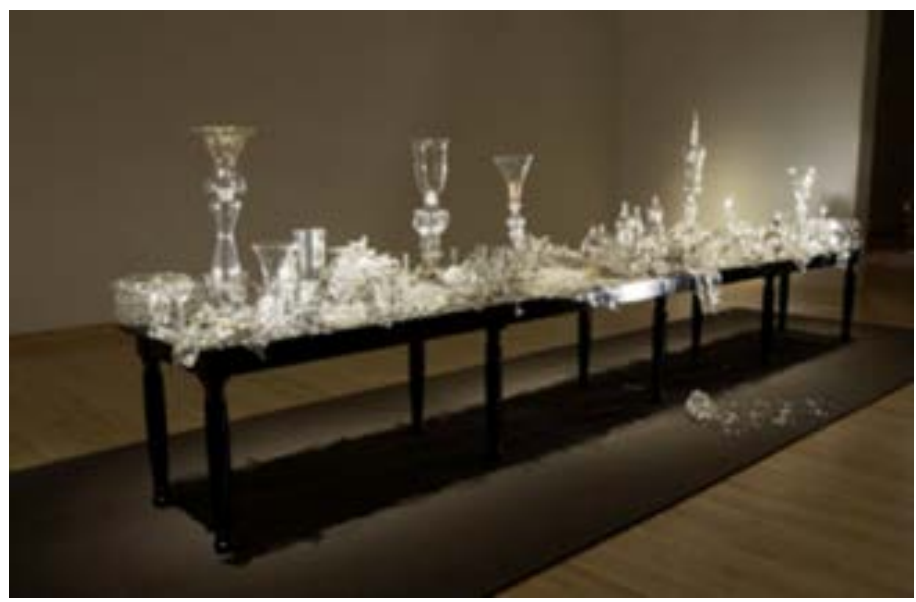

Figure 31.

Bancketje

(Banquet). Beth

Lipman. Glass,

oak, oil, mixed

media. 2003. 


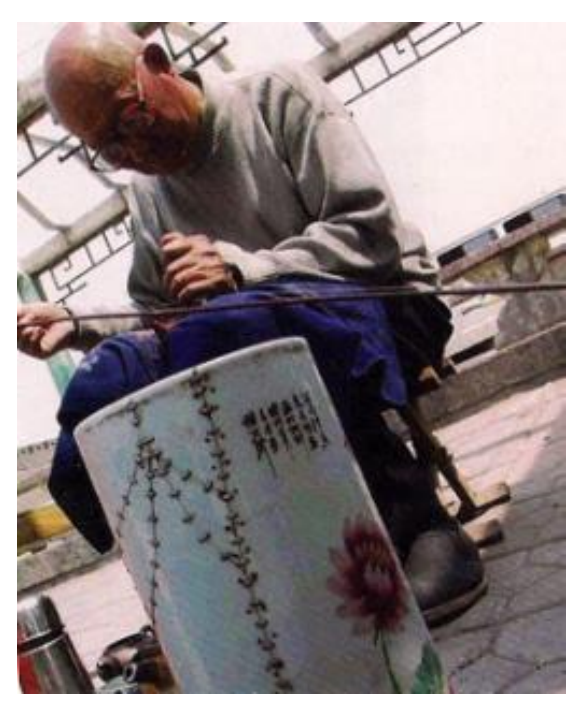

Figure 32.

Example of riveting on

Chinese porcelain by a

contemporary

"mender."
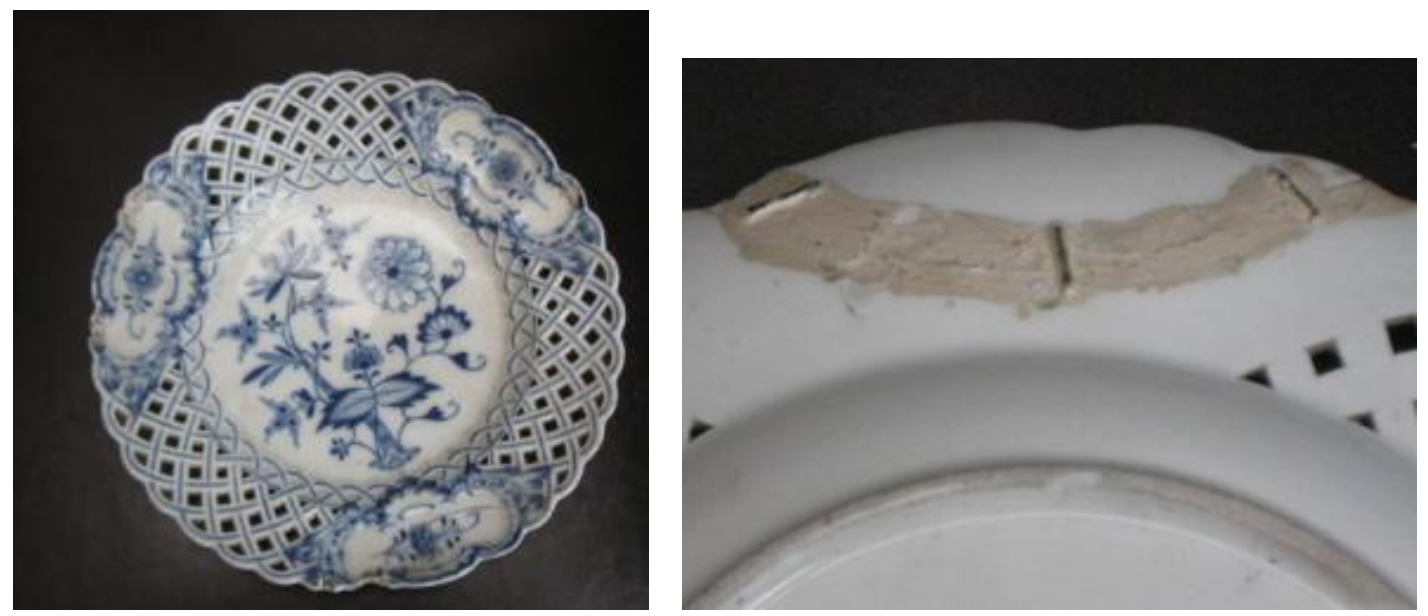

Figure 33.

Blue-Onion Pattern Serving Dish, Meissen, $18^{\text {th }}$ century.
Figure 34.

Blue-Onion Pattern Serving Dish, ceramic riveting detail, Meissen, $18^{\text {th }}$ century.

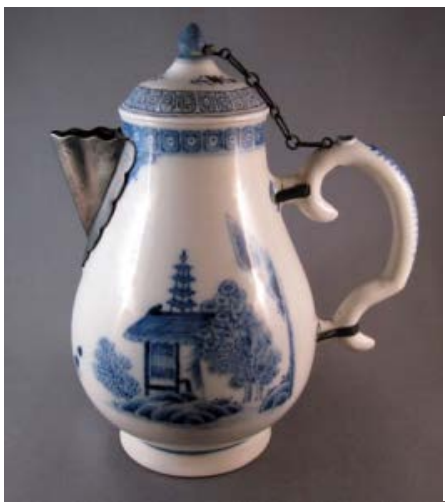

Figure 36.

Metal-spout replacement and handle reinforcement. Chinese porcelain, $18^{\text {th }}$ century. 


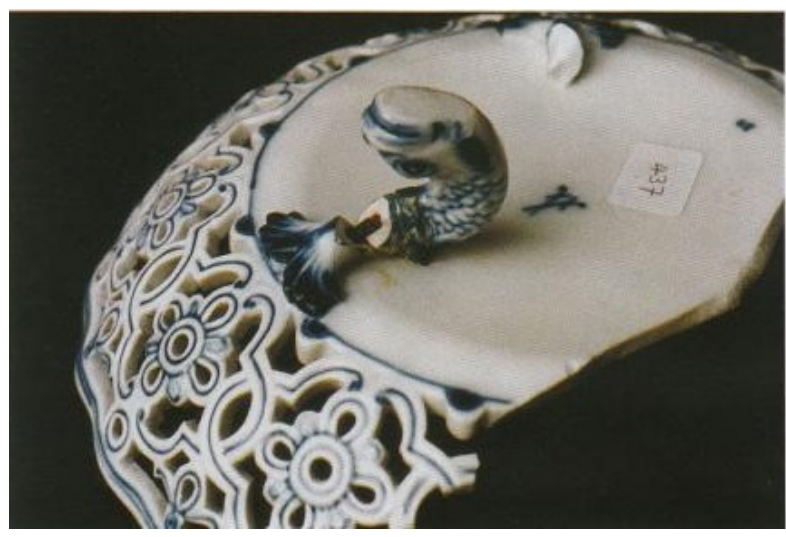

Figure 37.

Iron dowel securing the foot on an early$18^{\text {th }}$ century Meissen serving dish.

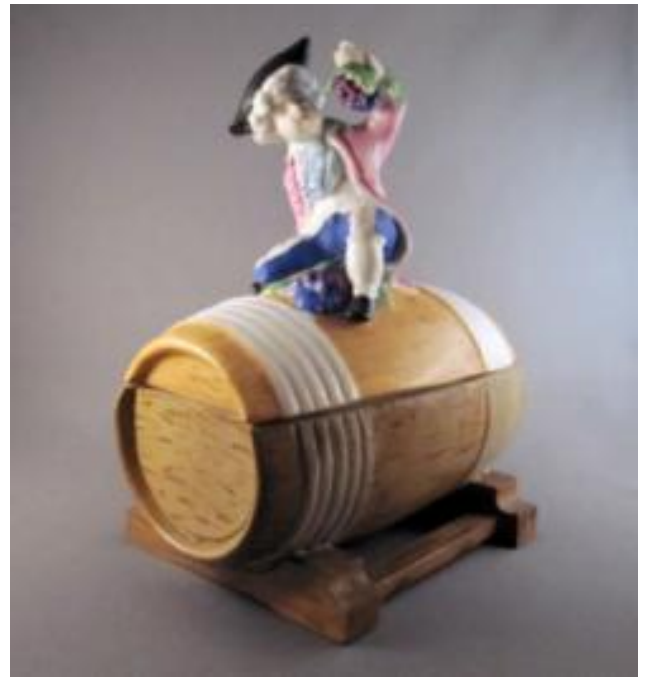

Figure 39.

Meissen figurine with wooden replacement, front.

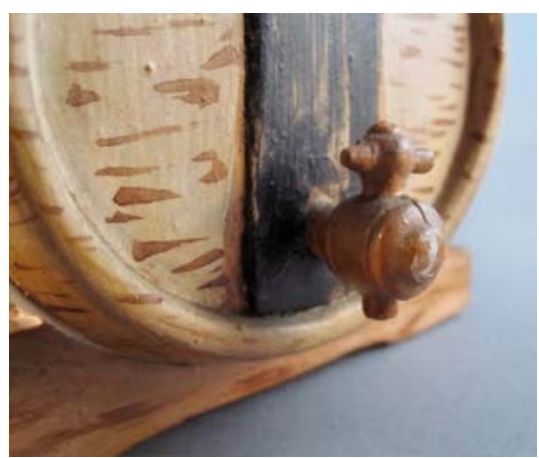

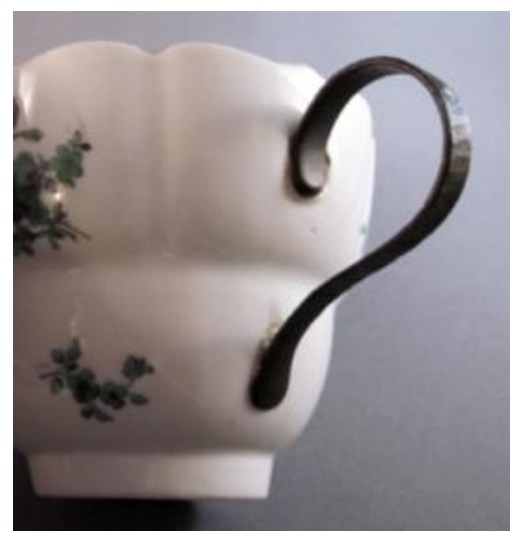

Figure 38.

Forged bronze replacement handle from 1800s, Meissen teacup.

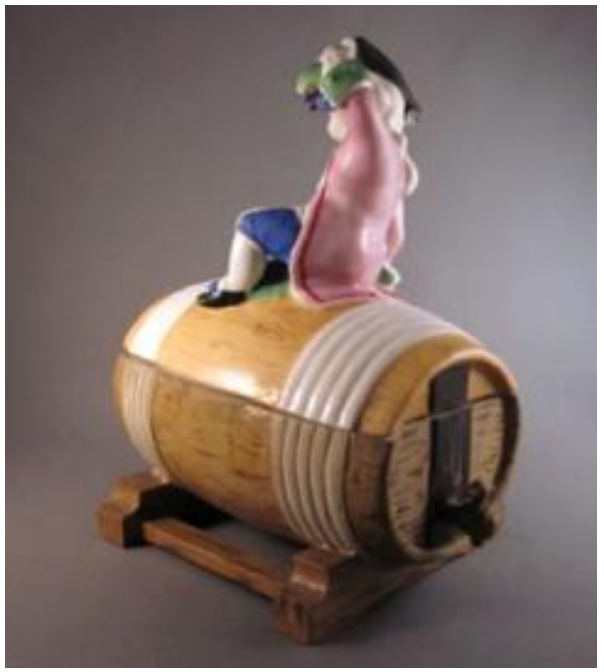

Figure 40.

Meissen figurine with wooden replacement, back.
Figure 41

Meissen figurine with wooden replacement, detail. 

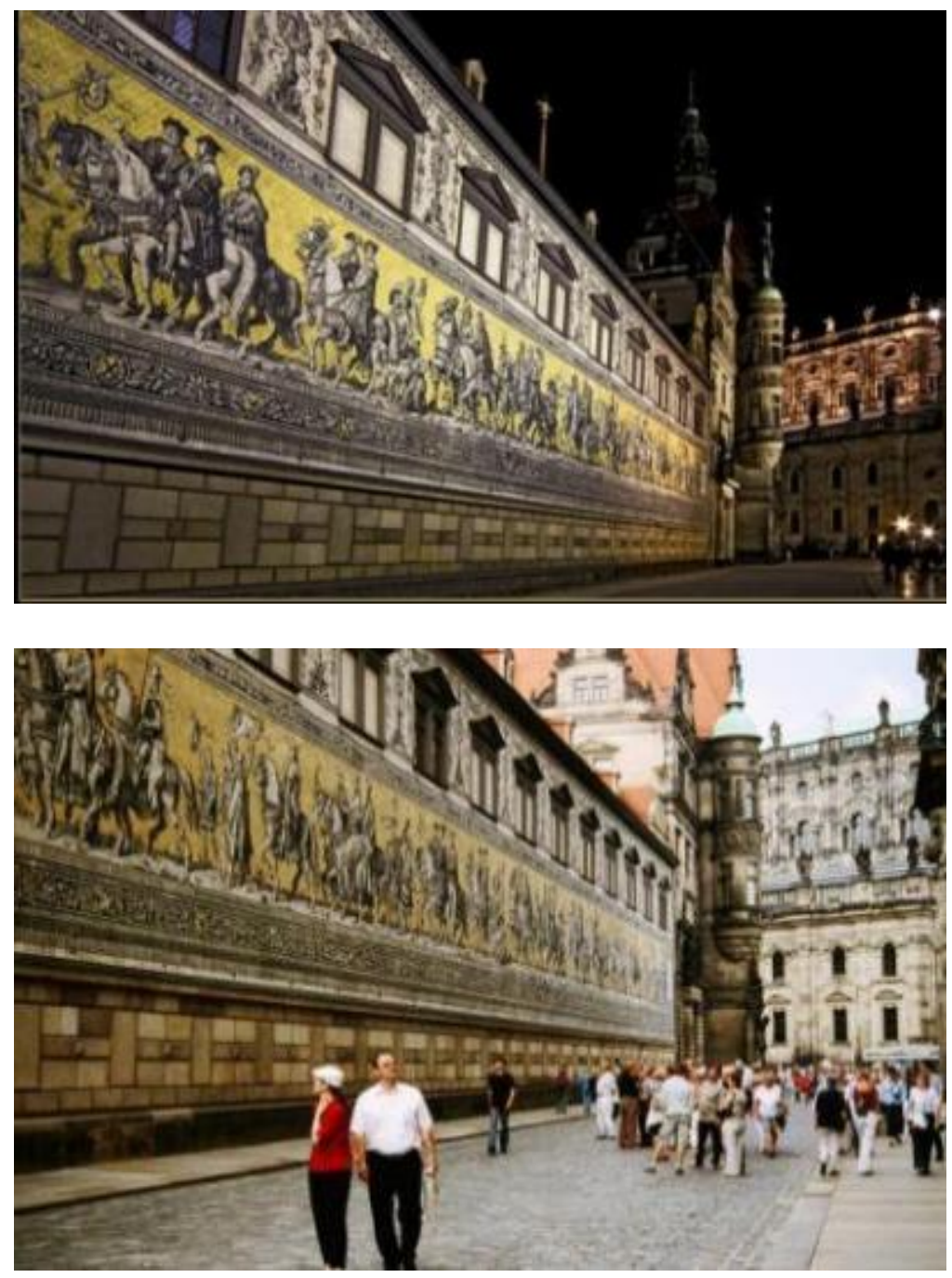

Figure 42. (left)

Fürstenzug mural, Saxony, Germany constructed in 1907.
Figure 43.

Fürstenzug mural, Saxony, Germany constructed in 1907.

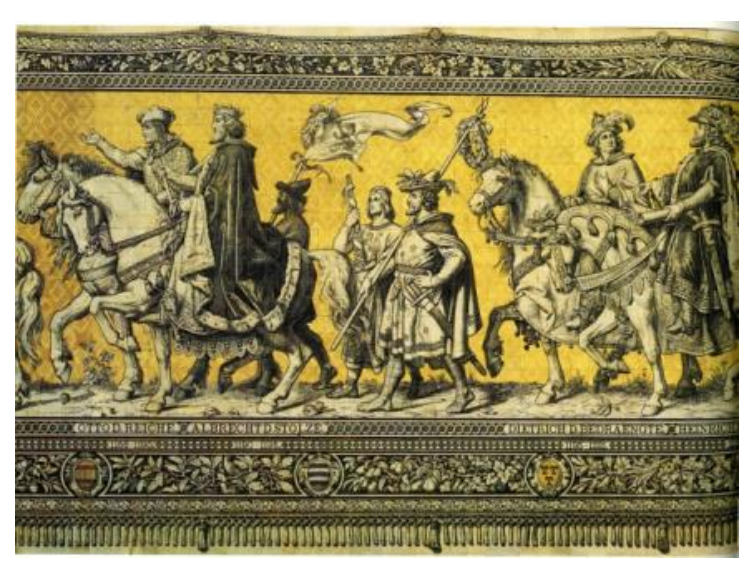

Figure 44.

Close-up of section of Fürstenzug mural displaying grand feu palette and decoration.

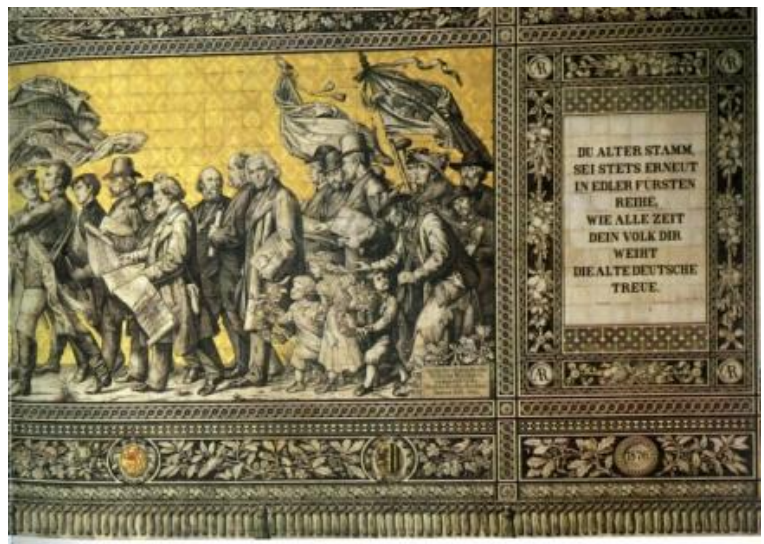

Figure 45.

Close-up of a section of Fürstenzug mural displaying contemporary painters, sculptors, and architects. 


\begin{tabular}{|l|l|}
\hline Compound & Percent Composition \\
\hline SiO2 & 59.0 \\
\hline Al203 & 35.2 \\
\hline K20 & 3.9 \\
\hline Na20 & 0.8 \\
\hline CaO & 0.3 \\
\hline MgO & 0.2 \\
\hline
\end{tabular}

Figure 46.

Chemical Composition of Meissen Porcelain

\begin{tabular}{|l|l|}
\hline Compound & Percent Composition \\
\hline SiO2 & 74.6 \\
\hline Al203 & 18.5 \\
\hline K20 & 3.4 \\
\hline CaO & 0.3 \\
\hline Ti02 & 0.09 \\
\hline MnO & 0.05 \\
\hline Fe203 & 1.4 \\
\hline
\end{tabular}

Figure 47.

Chemical Composition of Chinese Porcelain.

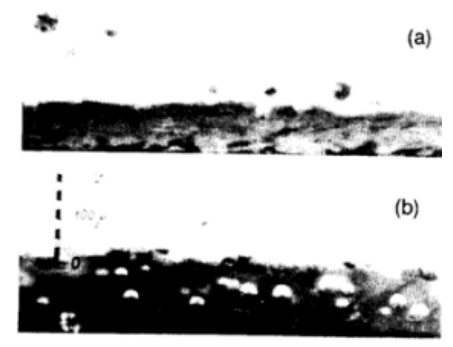

(c)
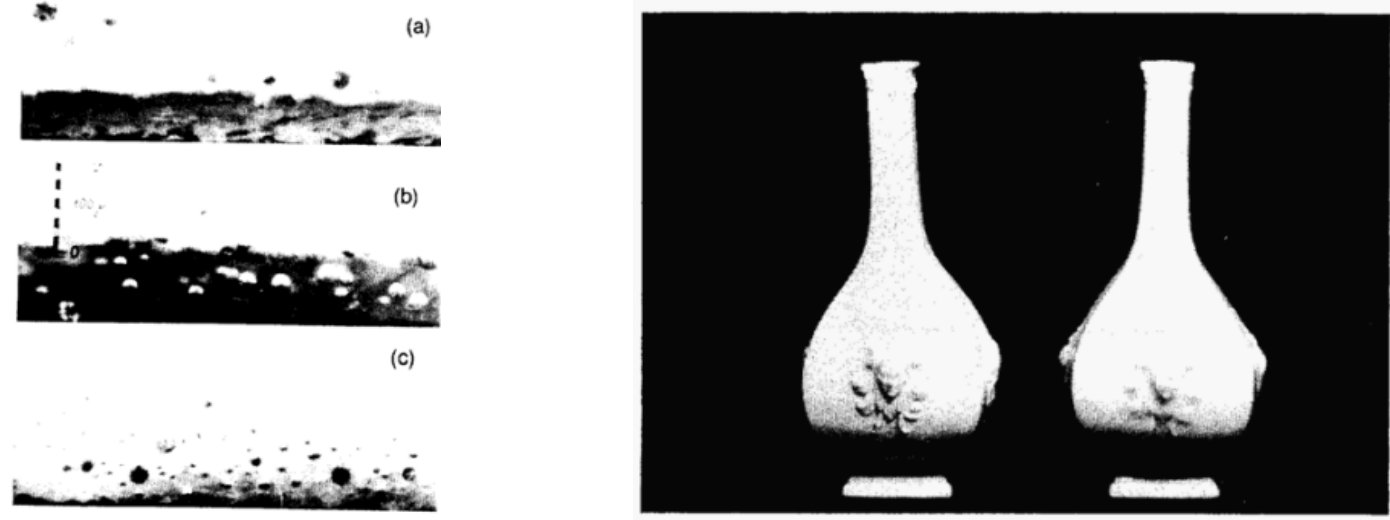

Figure 48.

Glaze of nineteenth century Meissen porcelain (a) is thin and bubble-free compared with contemporary porcelains $(\mathrm{b}, \mathrm{c}$. $)$

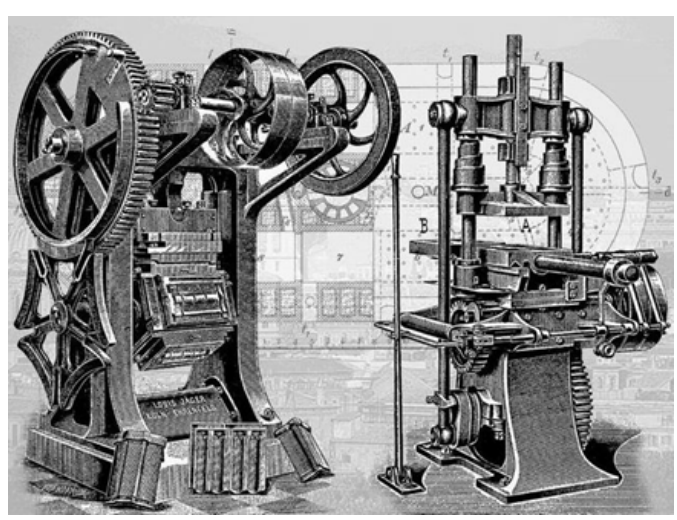

Figure 50.

Example of late $19^{\text {th }}$ century ceramic tile press.

Figure 49.

Detail of decoration on Bottger porcelain is concealed by thick glaze of contemporary reproduction shown on right.

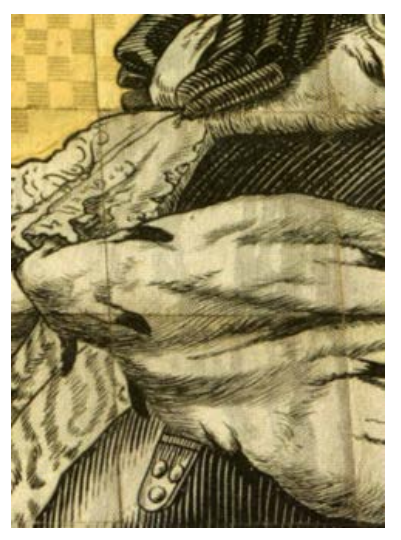

Figure 51.

Close-up of possible slip pigment bleeding or leaching. 


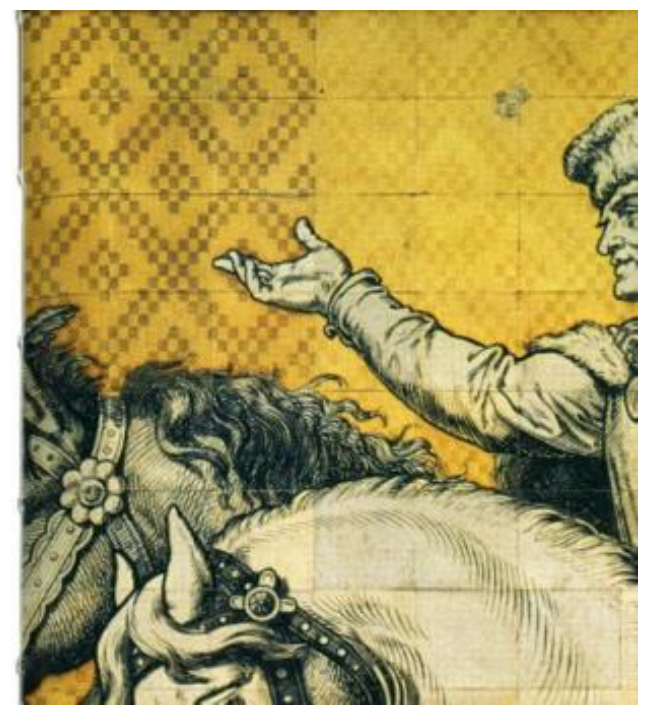

Figure 52.

Example of tile discoloration.

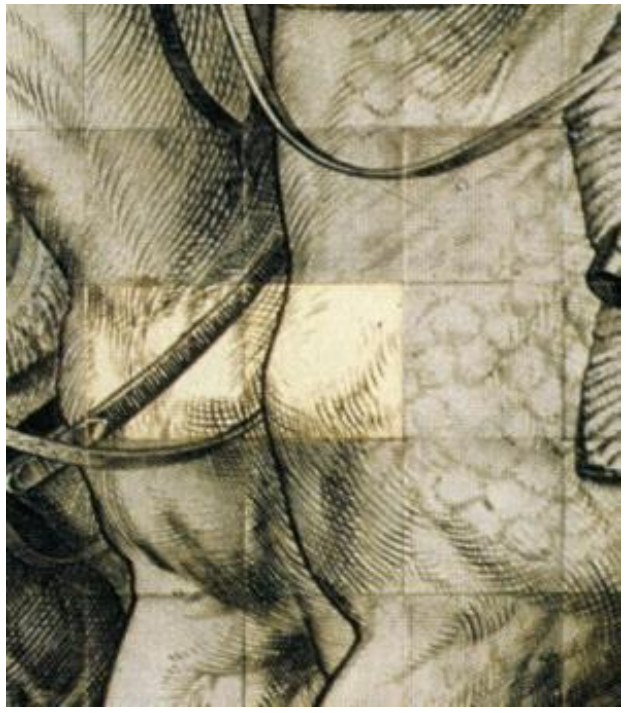

Figure 53.

Example of tile discoloration.

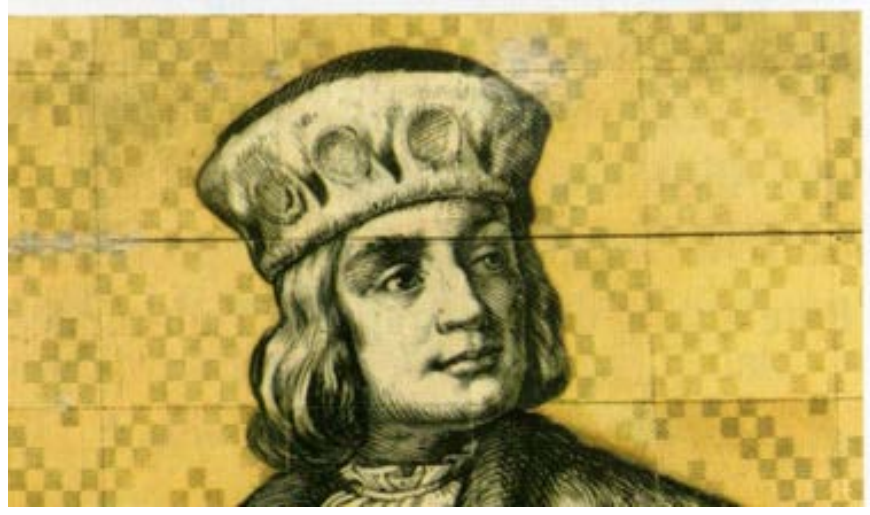

Figure 54.

Example of tile separation.

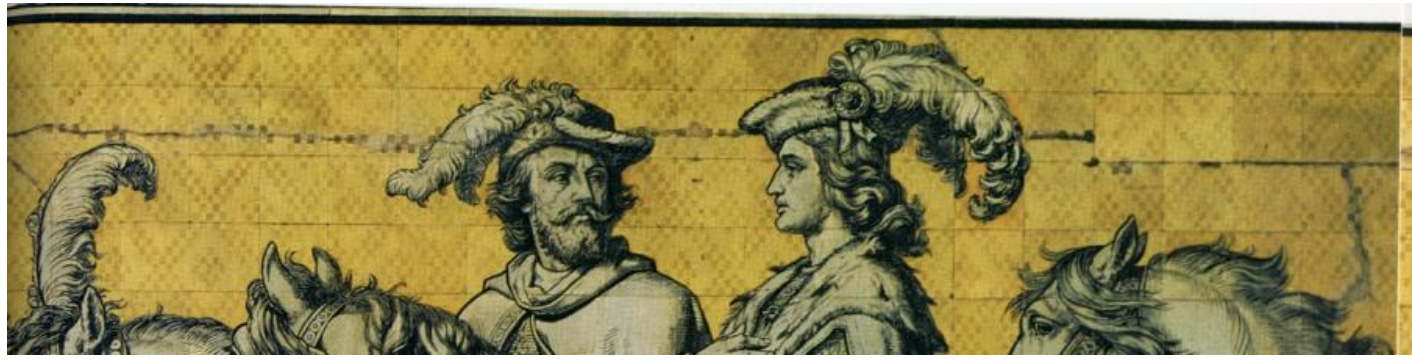

Figure 55.

Example of severe lateral cracking. 


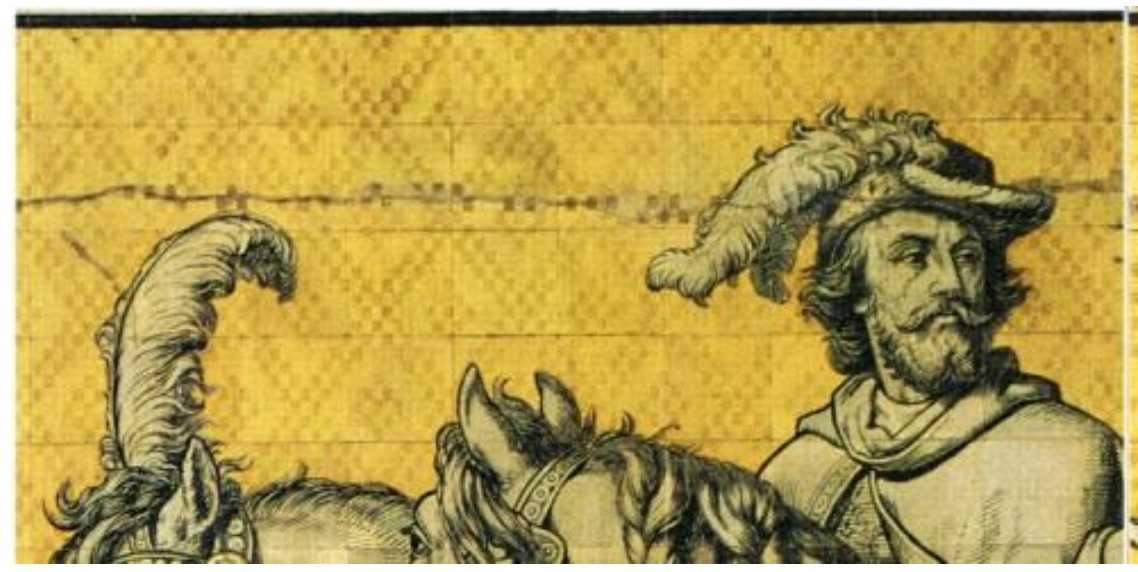

Figure 56.

Example of both

lateral cracking and pigment

discoloration.

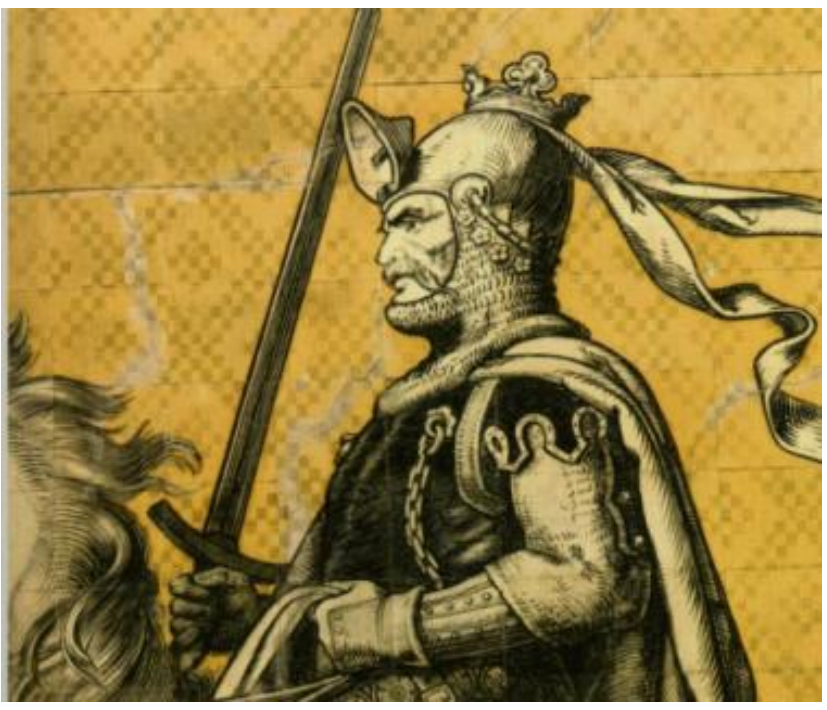

Figure 57.

Example of lightened or yellow adhesive from previous restoration.

Note: Figures 48 and 49 are attributed to A. D'Albis' work from "The History of Innovation in European Porcelain Manufacture and the Evolution of Style; Are They Related?" in Technology and Style, Vol. 2, 1986: 398-399. 


\section{Bibliography}

Appelbaum, Barbara. "Criteria for Treatment: Reversibility." Journal of the American Institute for Conservation 26 (1987): 65-73.

Barber, Edwin Atlee. Artificial Soft Paste Porcelain. New York: Doubleday, Page \& Company 1907.

Barnard, Julian. Victorian Ceramic Tiles. New York, Graphic Society Ltd. 1972.

Barnett, Alan W. Community Murals: The People's Art. Philadelphia. The Art Alliance Press, Inc., 1984.

BBC Radio. "BBC Radio 4: Voices of the Powerless," August 2002. http://www.bbc.co.uk/radio4/history/voices/voices_salisbury.shtml

Blaschke, Karlheinz. Der Fürstenzug Zu Dresden: Denkmal Und Geschichte Des Hauses Wettin. Urania Publishing 1991.

Braider, Christopher. Baroque Self-Invention and Historical Truth. England: Ashgate Publishing Ltd. 2004.

Brotton, Jerry. The Renaissance Bazaar: from the Silk Road to Michelangelo. Oxford University Press 2002.

Burton, William. Porcelain: Its Nature, Art, and Manufacture. London: B.T. Batsford Ltd. 1906.

Cassidy-Geiger, Maureen. "Graphic Sources for Meissen Porcelain: Origins of the Print Collection in the Meissen Archives." Metropolitan Museum Journal, 31 (1996): 99-126.

Cassidy-Geiger, Maureen. Fragile Diplomacy: Meissen Porcelain for European Courts ca. 1710-63. Yale University Press 2007.

Campbell, Bruce. Mexican murals in times of crisis. University of Arizona Press, 2003

Caple, Chris. Conservation Skills : Judgement, Method, and Decision Making. London and New York: Routledge, 2000.

D’Albis, A. "The History of Innovation in European Porcelain Manufacture and the Evolution of Style: Are They Related?" Technology and Style. 2 (1986): 397412. 
Davison, Sandra. "Reversible Fills for Transparent and Translucent Materials." Journal of the American Institute for Conservation 37 (1998): 35-47.

Delau, Reinhard. Der Fürstenzug in Dresden. Edition Seachsische Zeitung 2005.

Druesedow, Jean L. "In Style: Celebrating Fifty Years of the Costume Institute." The Metropolitan Museum of Art Bulletin, 45 (1987): 1-63.

Efremov, G.L. "Effect of the Shape and Distribution of Clay Particles on Shrinkage of Products." Glass and Ceramics 14 (1957): 1-6.

Foote, Helen S. "Vincennes and Meissen Porcelain," The Bulletin of the Cleveland Museum of Art, 39 (1952): 124-127.

Franco-Prussian War website. Accessed 11/12/2010. http://francoprussianwar.com/

Gaimster, David. German Stoneware 1200-1900: Archaeology and Cultural History. British Museum Press 1997.

Geschke, Rainer. "Ceramic Gap-Fills for Ceramic Restoration." The Conservator 28 (2004): 74-83.

Gleeson, Janet. The Arcanum: The Extraordinary True Story. New York: Warner Books 1998.

Gruber, Alain. The History of Decorative Arts: The Renaissance and Mannerism in Europe. New York: Abbeville Press Publishers 1993.

Hainbach, Rudolf. Pottery Decorating. London: Scott, Greenwood \& Son 1907.

Hausen, Clemens. Der Fürstenzug auf dem Sgraffito-Fries am Königl. Schlosse zu Dresden. Dresden, C. Heinrich Publishing 1903.

Holdridge, D.A. The Fine Ceramics Industry in Germany during the period 1939-1945. London: His Majesty's Stationary Office 1950.

Honey, W.B. Dresden China; an introduction to the study of Meissen porcelain. New York: Tudor Publishing Co. 1946.

Houston, Stephen D. “An Example of Preclassic Myan Writing?" Science 311 (2006): 1249-50.

Jacobs, Jane. Death and life of great American cities. New York: Random House, 1961. 
Kaufmann, Thomas Dacosta. Toward a Geography of Art. Chicago: University of Chicago Press 2004.

Kingery, W.D. “The Development of European porcelain.” Technology and Style 3 (1986): 153-178.

Kolb, Charles C. Ceramic Ecology Revisited: The Technology and Socioeonomics of Pottery. Oxford, BAR International Series 1988.

Koob, Stephen. "Obsolete Fill Materials Found On Ceramics." Journal of the American Institute for Conservation 37 (1998): 49-67.

Le Corbeiller, Clare, and Alice Cooney Frelinghuysen. "Chinese Export Porcelain: Patterns of Exchange." Metropolitan Museum of Art Bulletin 60 (2003): 5-60.

Löffler, Fritz. The Old Dresden - History of its Buildings. Leipzig: E.A. Seemann 1981.

Lees, Andrew. Cities, sin, and social reform in imperial Germany. University of Michigan Press, 2002.

Mauch Messenger, Phyllis. Ethics of Collecting Cultural Property: Whose culture? Whose property? University of New Mexico Press, 1989.

McNab Dennis, Jessie. “The Art of Meissen Chinoiserie." The Metropolitan Museum of Art Bulletin. 22 (1963):11.

Morley-Fletcher, Hugo. Antique Porcelain in color: Meissen. New York: Doubleday \& Company Inc. 1971.

Morley-Fletcher, Hugo. "Kändler, Johann Joachim." In Grove Art Online. Oxford Art Online, http://www.oxfordartonline.com/subscriber/article/grove/art/T045651

Morris, David and Karl Hess. Neighborhood Power : The New Localism. Boston: Beacon Press, 1975.

Neiro, Michaela. "Adhesive Replacement: Potential New Treatment for Stabilization of Archaeological Ceramics." Journal of the American Institute for Conservation 42 (2003): 237-244.

North, Michael and David Ormrod. Art Markets in Europe, 1400-1800. Great Britain: Ashgate Publishing 1998.

Parsons, Claudia Sydney Maria. China Mending and Restoration. London: Faber \& Faber 1963. 
Pennington, D.H. Seventeenth Century Europe. New York: Holt, Rinehart and Winston, Inc. 1970.

Prager, Brad. Aesthetic Vision and German Romanticism. New York: Camden House 2007.

Roemich, Hannelore. Glass and Ceramics Conservation 2010. ICOM Conference Publication, 2010.

Shaw, P.E. "The Magnetic Expansion of Some of the Less Magnetic Metals." Proceedings of the Royal Society of London 72 (1903-1904): 370-378.

Smith, Pamela H. Body of the Artisan : Art and Experience in the Scientific Revolution. University of Chicago Press, 2006.

Staubach, Suzanne. Clay. The History and Evolution of Humankind's Relationship with Earth's Most Primal Element. New York: Berkley Books 2005.

Steinberg, S.H. The Thirty Years' War and the Conflict for European Hegemony 16001660. New York: W.W. Norton \& Co. 1966.

Tennet, Norman H. The Conservation of Glass and Ceramics: Research, Practice, and Training. London: James and James Ltd. 1999.

Thirty Years' War homepage. "Thirty Years' War." http://www.strategos.demon.co.uk/tywhome/

Thornton, Jonathan. "A Brief History and Review of the Early Practice and Materials of Gap-Filling in the West." Journal of the American Institute for Conservation 37 (1998): 3-22.

Untermyer, Irwin. Meissen and Other Continental Porcelain Faience and Enamel. London: Thames and Hudson 1956.

Valentiner, Wilhem R. "German Stoneware." The Metropolitan Museum of Art Bulletin. 6 (1911):160.

Velimirovic, Boris, and Helga Velimirovic. "Plague in Vienna." Reviews of Infectious Diseases 11 (1989): 808-826.

Vieira, C. M. F. and S. N. Monteiro. "Evaluation of a plastic clay from the state of Rio de Janeiro as a component of porcelain tile body." Matéria 12 (2007): 1-7.

Vries, Jan de. European urbanization, 1500-1800. Harvard University Press, 1984.

Walcha, Otto. Meissen Porcelain. New York: G.P. Putnam's Sons 1981. 
Walker, Stefanie. "The Artistic Sources and Development of Roman Baroque Decorative Arts," in Life and the Arts in the Baroque Palaces of Rome, edited by Stefanie Walker and Frederick Hammond, 3-17. New York: Yale University Press, 1999.

Williams, Nigel. Porcelain Repair and Restoration. University of Pennsylvania Press, 2002.

Wood, Karen Ann. Tableware in Clay from Studio and Workshop. Marlborough Wiltshire: Crowood Press Ltd. 1999.

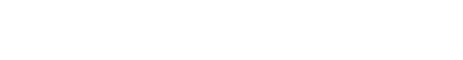

